$\mathrm{DOE} / \mathrm{TIC}-10289$

\title{
Energy Conservation in Ice Skating Rinks
}

\author{
Bruce K. Dietrich Department of Chemical Engineering \\ and \\ Goessmann Laboratory \\ Thomas J. McAvoy University of Massachusetts \\ Amherst, Massachusetts
}

1980

Prepared for

U.S. Department of Energy Assistant Secretary for Resource Applications Technical Information Center

Published by U.S. Department of Energy Technical Information Center 
This book was prepared as an account of work sponsored by an agency of the United States Government Neither the United States Government nor any agency thereof, nor any of their employees, makes any warranty, express or Implied, or assumes any legal liability or responsibility for the accuracy, completeness, or usefulness of any information, apparatus, product, or process disclosed, or represents that its use would not infringe privately owned rights Reference hereın to any specific commercial product, process, or service by trade name, trademark, manufacturer, or otherwise, does not necessarily constitute or imply its endorsement, recommendation, or favoring by the United States Government or any agency thereof The views and opınions of authors expressed herein do not necessarily state or reflect those of the United States Government or any agency thereof

International Copyright, () U.S. Department of Energy, 1980, under the provisions of the Universal Copyright Convention. United States copyright is not asserted under the United States Copyright Law, Title 17, United States Code.

Avallable as DOE/TIC-10289 for $\$ 5.50$ from

National Technical Information Service

U. S. Department of Commerce

Sprıngfıeld, Vırgınıa 22161

\section{DOE Distribution Category UC-95f}

Printed in the Unıted States of America

USDOE Technical Information Center Oak Ridge, Tennessee

Aprıl 1980 


\section{DISCLAIMER}

This report was prepared as an account of work sponsored by an agency of the United States Government. Neither the United States Government nor any agency Thereof, nor any of their employees, makes any warranty, express or implied, or assumes any legal liability or responsibility for the accuracy, completeness, or usefulness of any information, apparatus, product, or process disclosed, or represents that its use would not infringe privately owned rights. Reference herein to any specific commercial product, process, or service by trade name, trademark, manufacturer, or otherwise does not necessarily constitute or imply its endorsement, recommendation, or favoring by the United States Government or any agency thereof. The views and opinions of authors expressed herein do not necessarily state or reflect those of the United States Government or any agency thereof. 


\section{DISCLAIMER}

Portions of this document may be illegible in electronic image products. Images are produced from the best available original document. 


\section{Introduction}

In the entertainment business ice skating rinks are major per capita consumers of energy. In 1977, single rinks in Massachusetts had electric utility bills ranging from $\$ 20,000$ to $\$ 40,000$ and gas utility bills ranging from $\$ 10,000$ to $\$ 17,000$ for a 7 to 8 month season; average bills were $\$ 29,000$ and $\$ 14,000$, respectively. In most rinks electric energy use can be cut in half or more with investments of under $\$ 40,000$, and gas costs can be cut by an even larger fraction for an investment of under $\$ 25,000$. Rink owners, however, must be convinced that the equipment and new operating procedures actually work and have reasonably short payout times.

Most information on new equipment is provided by manufacturers. Thus the needed information is spread out over hundreds of pamphlets and advertising flyers. Furthermore, such information is not always trusted by rink owners since the primary purpose of the information is to sell equipment. Data on changes in rink operating procedures are usually given by ice rink consultants. This information varies from consultant to consultant and, of course, is not available to rinks that do not employ consultants. For these reasons, there is a need for a compact, commercially nonprejudiced source of information on what can be done to reduce energy costs in ice rinks.

This manual examines the most important areas in which energy and money can be saved in an ice rink, i.e., changes in operating procedure and the installation of energy saving equipment. It is based on experiments, case studies, and good engineering estimates.

The manual is written for rink owners and managers who do not have formal training in engineering but do have a fair practical knowledge of refrigeration systems. For this reason, most of the calculations and technical descriptions are not included in the text of the manual but are added as appendixes. 


\section{Acknowledgments}

We are grateful for the financial support provided by the Department of Energy and the Ice Skating Institute of America and for the equipment lent to us by the General Electric Company. We also wish to thank the following companies and individuals who provided invaluable data on costs and performance:

Walter Muehlbronner, Rink Manager, Wissahickon Skating Club, Philadelphia, $\mathrm{Pa}$.

Calmac Manufacturing Corp., Englewood, N. J.

John Connelly, Rink Design Consultants, Inc., Syracuse, N. Y.

Dennis Daly, Athletic Department, Amherst College, Amherst, Mass.

Sarah Gilchrest O'Leary, student, University of Massachusetts, Amherst, Mass.

John Heddle, Manager, Richfield Ice Rink, Richfield, Minn.

Paul Hogan, Supervisor, Rinks and Pools, State of Massachusetts

Holmsten Ice Rinks Inc., St. Paul, Minn.

ITT Ice Rinks, Midland Park, N. J.

Stephen Knisley, student, University of Massachusetts, Amherst, Mass.

Dennis May, Manager, Bloomington Ice Arena, Bloomington, Minn.

William Mueller, Chief Engineer, Amherst College, Amherst, Mass.

Zygamond Nash, Rink Manager, North Adams, Mass.

Michael O'Leary, student, University of Massachusetts, Amherst, Mass.

John O'Neil, Rink Manager, University of Delaware, Newark, Del.

Sentinel Energy Control Systems, Burlington, Mass.

George Shean, Engineer, State of Massachusetts

Sprague Electric Co., North Adams, Mass.

Ronald Venne, Rink Manager, Williston Academy, Easthampton, Mass.

J. F. Welch, Jr., Vice Chairman, General Electric Company, Fairfield, Conn.

Western Massachusetts Electric Co., Greenfield, Mass. 


\section{Contents}

Page 1

Page 3

Page 10

Page 12

Page 18

Page 19

Page 21

Page 23

Page 27

Page 38
The Potential for Reducing Energy Costs

Changes in Operating Procedure

Moderate Investments

Major Investments

Glossary and Abbreviations

Appendix 1: Adjustment of Savings and Payout Times to Account for Varying Utility Rates and Interest

Appendix 2: Interaction Between Different Modifications

Appendix 3: Refrigeration Systems and Heat Balances

Appendix 4: Calculations of Energy and Dollar Savings

Appendix 5: Heat and Mass Transfer Coefficients 


\section{Chapter 1}

\section{The Potential for Reducing Energy Costs}

The ever-increasing costs of electricity and gas have become a major factor in the budgets of all ice rinks. In Massachusetts, for example, utility bills now account for $20 \%$ to $30 \%$ of the annual operating costs for ice rinks. When utilities were less expensive, large outlays of time and/or money to conserve energy often were not warranted. Over the past 6 years, however, the cost of energy has risen three times faster than the cost of industrial equipment as measured by the Marshall and Stevens cost index. This increase is shown in Fig. 1. Moreover, with the present worldwide shortage of oil and with the nuclear power industry facing expensive modifications in operating procedures and equipment design, the outlook is for utility costs to continue to rise faster than equipment costs.

Faced with a future of ever-increasing utility costs, rink managers must take a fresh look at old operating procedures and continually review new equipment that is being designed to reduce the amount of energy needed to keep a rink open. Such an effort can be well rewarded; many rinks have made substantial savings in energy through a wide variety of changes.

For example, the electric energy use at the Richfield Ice Rink in Richfield, Minnesota, has been reduced every

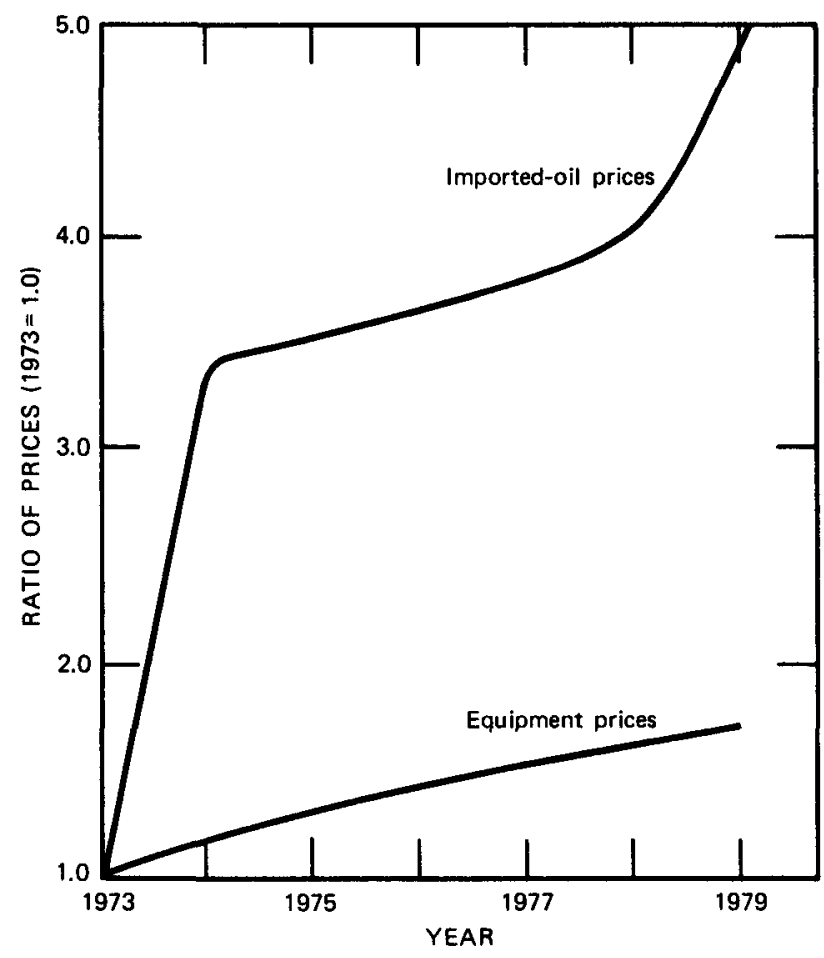

Fig. 1 Increase in equipment and oil prices since 1973. year since 1973. The total kilowatt-hour use for 1977 was $32 \%$ below that for 1973 . This saving was accomplished with a total investment of about $\$ 2500$. The Richfield energy reduction program included:

- Reducing the number of lights that are turned on for activities other than hockey.

- Shutting off the compressors at night and slowly reducing the slab temperature with a partially loaded compressor in the morning.

- Reducing the temperature of resurfacing water to $125^{\circ} \mathrm{F}$.

- Using a $2^{\circ} \mathrm{F}$ higher compressor suction temperature.

- Installing a snow-melting system that uses condenser waste heat.

Many other energy- and money-saving procedures are possible. At the University of Delaware rink both the electric and gas logs showed a 30\% drop following the installation of a nonradiating false ceiling. The Bloomfield, Minnesota, municipal rink reduced its heating bill by $\$ 10,000$ for the $1978 / 79$ season by heating one of their two rinks entirely with waste heat from the condenser. State-owned rinks in Massachusetts are reducing their energy use by:

- Installing industrial capacitors in all rinks.

- Installing an electronic refrigeration load cycler.

- Turning off the compressors and pumps or increasing the compressor suction temperature setting at night.

This manual describes and evaluates in detail the most important ways of reducing energy costs. Case studies of actual rinks, experimental findings, and energy calculations are included. The explanations are as nontechnical as possible; when technical terms must be used, they are fully explained. At the end of the manual is a glossary of the technical terms and abbreviations that are used throughout the manual. Five appendixes have been added. Appendixes 1 and 2 are aids in determining the cost savings; Appendixes 3 through 5 are written for engineers who might wish to explore energy-saving options further.

The modifications examined in this manual fall into three groups: changes in operating procedures, minor investments in new equipment (under $\$ 3000$ ), and major investments (over \$3000). The items considered in each category are:

- Changes in operating procedures

Reducing start-up costs.

Lowering the temperature of resurfacing water. 
Raising the refrigerant temperature.

Turning off the heat at night.

Turning off the compressor at night.

Turning off the pumps at night.

Proper ventilation during warm weather.

Dehumidification.

Reducing the ice slab thickness.

Reducing lighting intensity.

- Minor investments

Melting snow with condenser heat.

Preheating hot water with condenser heat.

Installing automatic demand limiters.

Increasing the rink power factor.

- Major investments

Installing a nonradiating ceiling.

Using condenser waste heat for space heating.

Installing electronic load-cycling equipment.

Replacing mercury lights with sodium or fluorescent lights.

The economic evaluation of the modifications in operating procedures is summarized by the savings in both kilowatt-hours and dollars per month. The evaluation of investments is summarized by the time in months (payout time) that it takes for the savings to pay for the equipment and its installation. For example, a consulting report to the Williston Academy in Easthampton, Massachusetts, on replacing their mercury lights with highpressure sodium lights predicts that monthly savings will be $\$ 225$ and the installed cost of the new system will be $\$ 7800$. Since the rink is only open for $8 \frac{1}{2}$ months per year, the annual savings from the new lighting system would be $\$ 225 \times 8.5$, or $\$ 1912$ per year. The payout time would then be $(\$ 7800 / \$ 1912) \times 12$, or 49 calendar months. As in this example, all payout times are given in calendar months. Interest payments are not included in the calculation of the payout times. Appendix 1, however, shows how payout times are increased for various interest rates.

The economics of some of the modifications depend on what other modifications are made at the same time. For example, any modification that reduces refrigeration use will reduce the amount of heat that can be recovered from the condenser for space heating. This and other interactions between possible modifications are discussed in detail in Appendix 2.

The economics of each modification depend on the local utility charges. The case studies presented are based on rates common in Massachusetts in 1979, i.e., electric energy at $\$ 0.035 / \mathrm{kWh}$ (includes the fuel-adjustment charge); electric demand at $\$ 3.50 / \mathrm{kW}$; gas at $\$ 0.32$ per hundred standard cubic feet (ccf); water at \$0.35/ccf; and sewer charges of $\$ 0.20 /$ ccf. The electric energy charge in kilowatt-hours ( $\mathrm{kWh}$ ) is based on the cost of fuel and labor to produce electricity. The electric demand charge in kilowatts $(\mathrm{kW})$ is based on the cost to the electric utilitv of interest and depreciation on its equipment. Charts presented in Appendix 1 show how payout times vary with utility rates. These charts can be used by rinks with utility rates that are significantly different from the base case rates. Rink owners should check their rates and, if necessary, consult these charts because substantial differences exist between various regions of the country. For example, in one section of Rhode Island, which borders Massachusetts, the electric energy rate is $\$ 0.05 / \mathrm{kWh}$ and the demand rate is $\$ 1.65 / \mathrm{kW}$. 


\section{Chapter 2 Changes in Operating Procedure}

\section{START-UP}

Ice-making time is a time of unusually high electric power consumption because both compressors are running. Because of the ratchet clauses in most electric utility rate schedules, these few days of high power use cause high electric demand bills throughout the year. The ratchet clauses set the minimum electric demand billing at $60 \%$ to $80 \%$ of that of the highest month of the previous year. For example, at the state-owned rink in Peabody, Massachusetts, the maximum electric demand was $248 \mathrm{~kW}$ during the start-up of the 1977 season. The utility schedule set the minimum billing at $80 \%$ of the kilowatt demand during the previous 11 months. Therefore, the rink was billed for 198 $\mathrm{kW}$ (or \$714) during the four months that the rink was shut down in the spring and summer of 1978.

Some electric companies have an optional determination of demand rate schedule. This rate schedule saves a rink from paying a demand charge when it is closed. Rink managers should check with their utility companies about different rate options.

Rink managers should take extreme measures to reduce all nonessential use of electricity for the few days during which they are making ice. By far the largest savings will come from the lighting system. Most rinks have 50 to 60 $\mathrm{kW}$ of lighting, including ice, aisle, and room lights. Not all these lights are on during ice making, but often many more lights are on than are really necessary. Every $10 \mathrm{~kW}$ of lighting that can be shut off while ice is being made is equivalent to a $\$ 20$ to $\$ 30$ monthly reduction in the electric bill during those months when electric demand is at the minimum set by the ratchet clause.

Electric appliances that could be shut off during ice making include: electric water heaters, soda dispensing machines, small refrigerators for the personal use of the staff, and all small electric heating units. For example, something as small as an immersion heater for heating soup or coffee water uses $\mathbf{4 0 0}$ watts and will cause an increase of $\$ 1$ in electric demand charges for every month that the ratchet clause is in effect.

\section{RESURFACING WATER TEMPERATURE}

Most rinks use heated water to resurface the ice. Hot water flows more evenly onto the ice and bonds more strongly to the old ice than does cold water. The reason for this is that hot water melts some of the old ice, smoothing out small cracks and flaws in the ice. Water that is hotter than necessary, however, is a waste of energy and money.
Can warm or cold water, rather than hot water, be used to resurface the ice? Experiments with warm water were carried out at Orr Rink in Amherst, Massachusetts. For one week the temperature of the resurfacing water was reduced from $180^{\circ} \mathrm{F}$ to between $130^{\circ} \mathrm{F}$ and $140^{\circ} \mathrm{F}$. No apparent deterioration in the ice quality was observed by the high school hockey teams using the rink or by the Zamboni operators.

The answer to the question of using cold water to resurface is less clear. Zamboni operators at Orr Rink in Amherst claim that resurfacing with cold water creates a surface which is more easily cut up during hockey. They also claim that the new ice does not bond to the old ice as well when cold water is used. Managers of state-owned rinks in Massachusetts have experienced puddle formation when cold water is used, and they think $120^{\circ} \mathrm{F}$ is the minimum temperature for resurfacing. However, $12 \%$ of indoor rinks are resurfaced with cold water, and at least one ice rink consultant recommends this practice. Another resurfacing policy alternates cold-water resurfacing and hot-water resurfacing.

How much money can be saved by resurfacing with warm or cold water? The savings depend on how many times the rink is resurfaced, the volume of water used for resurfacing, the type of water heater used, and, to a lesser extent, the type of refrigeration system used in the rink. Consider, for example, a rink that is resurfaced 8 times a day, uses a brine refrigeration system, uses a gas water heater to heat 180 gallons of water to fill the Zamboni, and uses 140 of those 180 gallons to resurface the ice. If the temperature of the resurfacing water is reduced by $50^{\circ} \mathrm{F}$, this rink will save $600,000 \mathrm{Btu}$ of gas energy per day, or $\$ 82 /$ month. A Btu is a standard unit of heat and is equal to the heat necessary to raise the temperature of 1 pound of water $1^{\circ} \mathrm{F}$. Additional savings result from the reduced refrigeration load. A conservative estimate of the refrigeration savings is $23 \mathrm{kWh} /$ day or $\$ 24 /$ month. Total monthly savings would be $\$ 106$. Rinks with direct refrigeration systems would show savings about $4 \%$ to $5 \%$ smaller since these refrigeration systems are more efficient.

The estimates of savings are based on the assumption that the amount of resurfacing water is not increased as the temperature of the resurfacing water is lowered. An increase in the volume of water that must be frozen into new ice will decrease the expected savings. For example, if, when the temperature of the resurfacing water is lowered from $180^{\circ} \mathrm{F}$ to $130^{\circ} \mathrm{F}$, the volume of water is increased from 140 gallons to 160 gallons, the increase in resurfacing 
water volume will decrease the savings from $\$ 106 /$ month to $\$ 78 /$ month. If the volume of water were increased to 180 gallons, the savings would be reduced to $\$ 51 /$ month.

Figure 2 summarizes the savings that are possible from using warm $\left(130^{\circ} \mathrm{F}\right)$ or cold $\left(60^{\circ} \mathrm{F}\right)$ water for resurfacing if the amount of resurfacing water is not increased. How much the temperature of resurfacing water can be lowered is a question that each manager must answer by considering the activities of his rink. However, Fig. 2 shows that substantial savings are possible even without going to cold water. Obviously the Zamboni should not be filled with more hot water than is needed for the resurfacing.

\section{INCREASE IN REFRIGERANT TEMPERATURE}

Rink brine (or compressor suction) temperatures vary considerably even for rinks with the same activities. Hockey players often insist on having the coldest and hardest ice possible to minimize surface cutup. But what is the cost of maintaining ice that is colder than necessary? If the cost is substantial, a rink manager may want to raise the ice temperature by $1^{\circ} \mathrm{F}$ or $2^{\circ} \mathrm{F}$, provided the ice surface remains hard enough for normal activities.

Higher brine temperatures result in lower refrigeration costs for two reasons. First, the rate at which heat enters the ice slab depends on the temperature of the ice. As the ice temperature goes up, the amount of heat that must be removed per hour by the refrigeration system goes down. Second, higher brine temperatures result in an increase in the coefficient of performance (COP) of the compressor. The coefficient of performance is a measure of the

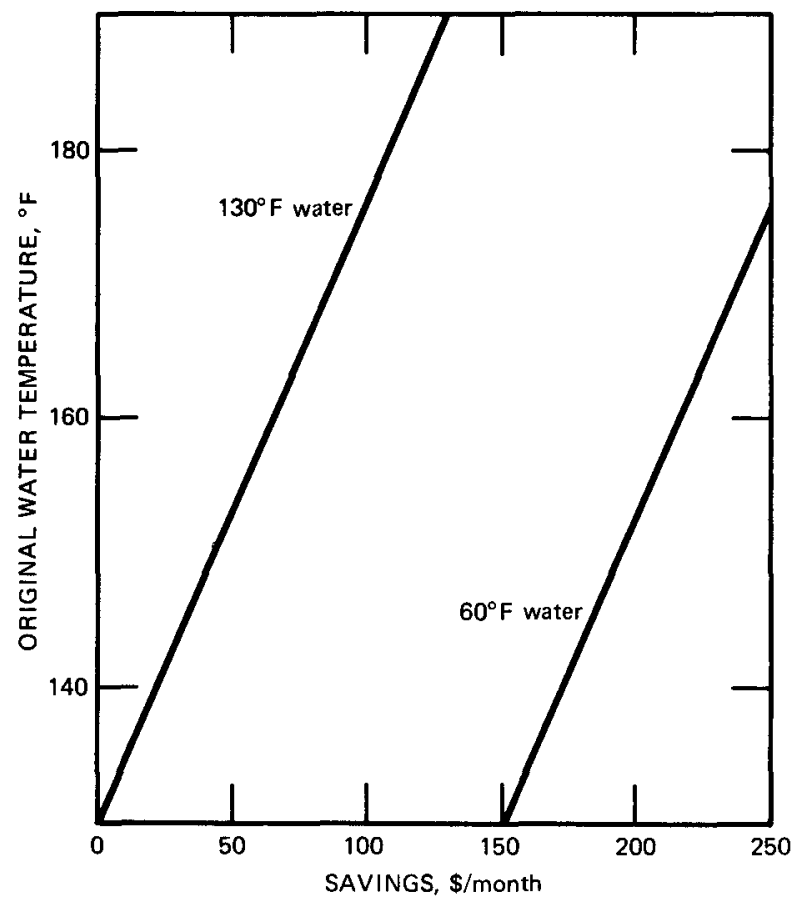

Fig. 2 Savings possible from using warm $\left(130^{\circ} \mathrm{F}\right)$ or cold $\left(60^{\circ} \mathrm{F}\right)$ water for ice resurfacing. efficiency of a refrigeration system. Specifically, the COP is. . the ratio of the amount of heat removed by the refrigeration system to the amount of work done in running the refrigeration system. For example, the COP is increased by over $9 \%$ when the compressor suction temperature is increased from $10^{\circ} \mathrm{F}$ to $15^{\circ} \mathrm{F}$. Therefore, in addition to the reduction due to the lower rate of heat transfer, the kilowatt-hours necessary to run the refrigeration system would be reduced by $9 \%$.

Experiments were done at the North Adams, Massachusetts, rink to determine the cost of lowering the brine temperature. The rink was used primarily for figure skating, and the normal ice-surface temperature (temperature at top of ice) was $26^{\circ} \mathrm{F}$. Every other week, the brine temperature was lowered $1^{\circ} \mathrm{F}, 2^{\circ} \mathrm{F}$, or $3^{\circ} \mathrm{F}$ below the normal value of $22^{\circ} \mathrm{F}$. At each brine temperature the kilowatt-hours, rink air temperature, and relative humidity were recorded for that week. During alternate weeks the brine temperature was returned to the normal value of $22^{\circ} \mathrm{F}$, and the measurements were repeated. With these data the kilowatthours used during a week with a lower brine temperature could be compared with the average kilowatt-hour use at normal brine temperature for the weeks immediately preceding and following the week with a lower temperature. This method averaged out the gradual increase in outdoor temperature and humidity. With in the rink, there was no change in the air temperature $\left(50^{\circ} \mathrm{F}\right)$ and only small changes in the relative humidity.

Logs of the kilowatt-hour use by a municipal rink in Richfield, Minnesota, were also obtained for a period when there was a decrease in the slab base temperature from $20^{\circ} \mathrm{F}$ to $18^{\circ} \mathrm{F}$.

Figure 3 shows the savings possible from raising the brine or slab temperature. The estimated dollar savings are based on a monthly electric utility bill of $\$ 4000$, the average bill for Massachusetts rinks in 1979. The savings are so large that every manager should be certain that his ice is not too cold for the current major activity.

Two additional points about brine temperature should be noted. First, when the brine temperature is raised, the ice gets soft and is thus more likely to be cut up during large public skating sessions. Second, rink managers may want to vary brine temperatures, using higher brine temperatures in the coldest months, rather than using a single temperature for the entire season.

\section{TURNING OFF THE HEAT AT NIGHT}

Lowering the thermostat setting at night is an obvious way of reducing heating costs in an ice rink. The savings that result go beyond those available to homeowners and stem from the reduced heat loads on the refrigeration system.

At night $50 \%$ to $60 \%$ of the load on the refrigeration system is a convective load. The convective refrigeration load refers to that part of the refrigeration load due to the 
movement of air in which warm, moist air from the rink is brought into contact with the ice. The convective refrigeration load includes freezing the water vapor deposited onto the ice by moist air (convective mass transfer) and the heat transferred to the ice from the warmer air (convective heat transfer).

The amount of heat transferred to the ice by air currents increases as the speed of the air currents increases and is directly proportional to the difference between the temperature of the air and that of the ice surface. Heating the rink at night keeps the air temperature from dropping and thus adds to the load on the refrigeration system. Equally important, heating the rink stirs up the air, and an increase in the air velocity from 0 to $1 \mathrm{mph}$ will increase the convective refrigeration load by $50 \%$ even if the temperature and humidity of the air are constant.

Radiant heat from the ceiling is an additional major heat load. This type of heat load is discussed in detail in the section on Nonradiative Ceilings. Briefly, radiative heat does not depend on moving air to carry heat to the ice. Instead, radiative heat passes right through the air in the same manner as light. The amount of heat radiated to the ice by the ceiling drops rapidly as the temperature of the ceiling drops. For example, if the ceiling temperature is reduced from $60^{\circ} \mathrm{F}$ to $50^{\circ} \mathrm{F}$, the amount of radiative heat is reduced by over $30 \%$. Since the radiative heat load accounts for $25 \%$ to $35 \%$ of the total refrigeration load, the savings

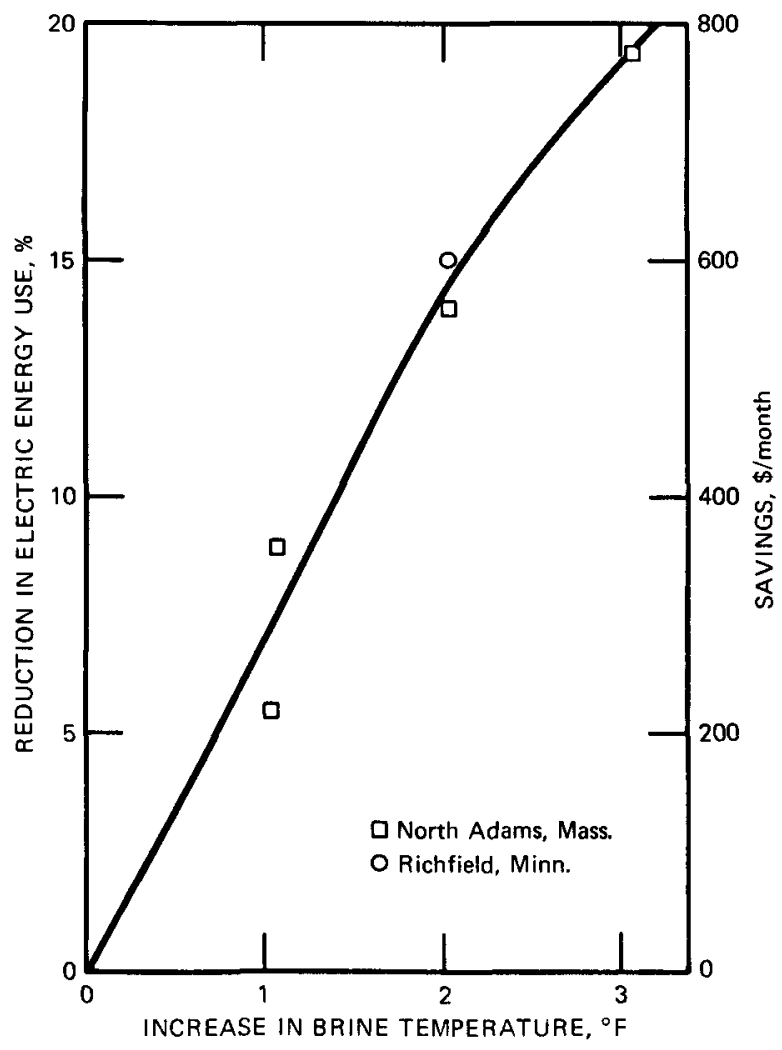

Fig. 3 Savings from raising the brine temperaturs. that come from reducing the ceiling temperature at night are substantial.

As an example of the total refrigeration savings, the temperature at the North Adams, Massachusetts, rink is maintained at $50^{\circ} \mathrm{F}$ during the day and is allowed to fall to $30^{\circ} \mathrm{F}-40^{\circ} \mathrm{F}$ at night during late winter. Heat is turned on only to prevent freeze-up in the pipes and equipment. If, instead, the temperature were maintained at $50^{\circ} \mathrm{F}$ by turning the heaters on for one-fifth of the night, and, if it is assumed that an air current of $1 \mathrm{mph}$ is created for one-fifth of the night, the total night refrigeration bill would be increased by over $32 \%$. This increase would be in addition to the increased cost of the gas to fuel the heaters. The actual savings will vary throughout the season, but an average value of $3000 \mathrm{kWh} /$ month or $\$ 105 /$ month $(3000$ $\mathrm{kWh} \times \$ 0.035 / \mathrm{kWh})$ is a conservative estimate for November through March for Massachusetts rinks.

\section{COMPRESSOR SHUTDOWN AT NIGHT}

Shutting down the refrigeration system at night is much like turning down a home thermostat at night. The energy savings result from a smaller temperature difference between the air and the ice surface. When the compressor is off at night, the temperature of the ice surface rises, and the difference between the air and ice-surface temperatures decreases. This smaller temperature difference causes a decrease in the amount of heat entering the ice slab and a decrease in the refrigeration load.

The resulting savings are proportional to both the rise in ice temperature and the length of time that the ice temperature is above normal. Therefore, the savings will be appreciable only if the refrigeration system can be shut down long enough for the ice to warm up significantly (preferably, 4 to $6 \mathrm{hr}$ ). An additional 1 to $2 \mathrm{hr}$ is needed for the ice temperature to recover after the compressor is turned on. Increasing the brine or ice slab temperature setting by 5 to $7^{\circ} \mathrm{F}$ for the night rather than shutting off the compressor results in similar savings. This latter procedure avoids the possibility of the ice's getting too warm and melting since the compressors will come on, if needed, to maintain the new, higher brine temperature.

How much energy and money can be saved by turning off the compressors at night? One ice rink consultant estimates that up to $10 \%$ of the total refrigeration bill can be saved by this technique. $\mathrm{He}$ also finds that the refrigeration system can be shut down for 8 to $10 \mathrm{hr}$ at a time during the winter in northern states and still maintain ice of good quality with 1 to $2 \mathrm{hr}$ of refrigeration in the morning. He finds that up to $6 \mathrm{hr}$ of compressor shutdown is possible at other times of the year.

Electric energy use was measured at Orr Rink in Amherst, Massachusetts, to determine the exact energy savings and temperature rise in a rink with an older, conventional ammonia/brine refrigeration system. Table 1 
summarizes the energy use and ice surface temperatures during a 3-week period in February. In all cases the measured kilowatt-hour use included the start-up period following shutdown until the refrigeration system brought the ice temperature back down to normal $118^{\circ} \mathrm{F}$ to $19^{\circ} \mathrm{F}$ with no skaters on the ice). The start-up time for the ice temperature to return to normal was 1 to $2 \mathrm{hr}$ at Orr Rink. Rinks with direct refrigeration systems would have quicker recovery times.

The major drawback in shutting off the compressor at night is the subsequent heavy use of both compressors in the morning to bring the temperature down to normal. This heavy use does not increase the electric energy bill ( $k W h$ ), but it can push up the electrical demand bill (kW). If nothing is done about this heavy use, the increase in electrical demand charges will equal or exceed the savings from the reduced kilowatt-hour use.

The most direct method of reducing the kilowatt demand is to use a timer to turn on the primary compressor 1 to $2 \mathrm{hr}$ before the opening skating session and to leave the secondary compressor shut off until the brine temperature is down to normal. Some rink managers have been reluctant to try this because the second compressor would not be immediately available if the primary compressor broke down, unnoticed by the rink operator. However, at least during winter operation in the north, even if the primary compressor failed to turn on in the early morning, the ice quality should not deteriorate significantly by 7:00 a.m. By then, the situation could be corrected by the morning operator.

A second method has been used by some operators of Massachusetts state-owned rinks. In the morning, the brine temperature setting is reduced by $0.5^{\circ} \mathrm{F}$ or $1^{\circ} \mathrm{F}$ over a 15 to $30-\mathrm{min}$ period. With this procedure, the difference between the actual brine temperature and the brine setting is kept small enough so that the second compressor does not come on. Since this procedure takes a substantial amount of time to bring the brine temperature to the optimum for skating, the compressor is usually not shut down on nights when skating sessions are to be held very

Table 1 Savings (kWh) with

Compressor Shutdown at Night

\begin{tabular}{llll}
\hline & \multicolumn{3}{c}{ Hours of compressor shutdown } \\
\cline { 2 - 4 } & 0 & 3.5 & 6 \\
\hline $\begin{array}{c}\text { Initial ice-surface } \\
\text { temp., }{ }^{\circ} \mathrm{F} \\
\text { Maximum ice-surface } \\
\quad \text { temp., }{ }^{\circ} \mathrm{F}\end{array}$ & 18.7 & 18.1 \\
$\begin{array}{c}\text { Electricity use from } \\
\text { 10 p.m. to 6 a.m., kWh }\end{array}$ & 864 & 722 & 574 \\
$\begin{array}{l}\text { Savings/day, kWh } \\
\text { Savings/month } \\
\text { (@\$0.035/kWh), \$ }\end{array}$ & 142 & 290 \\
\hline
\end{tabular}

early in the morning. If the compressor is to be shut down at night regularly, a timer can be purchased that will reduce the brine temperature setting automatically. This alleviates the problem of having someone forget to turn down the temperature setting or turning it down so much that both compressors are on. The brine temperature could also be lowered automatically by the load controller discussed later.

A third, but less desirable, method is available to rinks that have compressors that can be unloaded. One rink manager has rewired his compressors so that he can force the compressor to run unloaded no matter how far the actual brine or ice temperature is from the setting. He uses a timer to turn on the unloaded compressor $2 \mathrm{hr}$ before the opening skating session. However, ice rink equipment manufacturers generally do not recommend forcing a compressor to run unloaded for long periods of time. This mode of operation uses lubricating oil at a higher rate and reduces the ultimate life of the compressor, since an unloaded compressor must run longer to achieve the same amount of cooling as a fully loaded compressor. In addition, for a given amount of refrigeration, it is more economical to run a compressor fully loaded for a short period of time than it is to run an unloaded compressor for a longer time.

In summary, shutting down the refrigeration system at night should not adversely affect the ice quality and can save $\$ 100$ to $\$ 300$ per month. In the preparation of this manual, information on the effects of turning off the compressors at night was gathered only from northern rinks, primarily from rinks in Massachusetts. If a rink manager decides to turn off his compressors, he must decide how he will prevent both compressors from running at the same time after start-up, otherwise the kilowatt-hour savings will be an illusion, matched by higher kilowatt demand charges.

\section{TURNING PUMPS OFF AT NIGHT}

If the compressors are turned off at night, additional savings can be realized by shutting down the brine system. This procedure will not harm the pumps if they do not freeze up at night. The electric energy used in pumping the brine through the pipe grid beneath the rink is converted into heat by friction within the pipes. This heat must then be removed by the refrigeration system. Thus you save twice in turning off the pumps at night, once for the electricity to run the pumps and again for the refrigeration to remove the heat generated by the pumping.

The savings depend on the size of the pumps and the length of time that they are off at night. Conventional Freon/brine or ammonia/brine refrigeration systems use 20or 25-hp pumps, and plastic mat refrigeration systems have smaller 5-hp pumps. Figure 4 shows the savings that result from shutting the pumps off for various lengths of time. 


\section{PROPER VENTILATION DURING WARM WEATHER}

Ventilation is necessary to replace stale air in the rink and to prevent the buildup of fumes from the Zamboni. Too much ventilation, however, can be expensive during warm weather. During this time, the incoming air is warm and humid, and the cost of removing the moisture and cooling the air is substantial.

To cool and dehumidify the air in a typical low-roofed rink from $80^{\circ} \mathrm{F}$ and $90 \%$ relative humidity to $50^{\circ} \mathrm{F}$ and $50 \%$ relative humidity requires 2.1 million $B t u$ of refrigeration. Rinks with high rounded ceilings would require a substantially higher amount of refrigeration. For lowroofed rinks the refrigeration costs approximately $\$ 6.00$, an amount that seems small until it is realized how often a ventilation fan can replace the air in a rink. Two 30-in. fans will bring in air equivalent to the volume of the rink every $45 \mathrm{~min}$, and two 48-in. fans will turn over the air in the rink in $18 \mathrm{~min}$.

Since forced ventilation raises the cost of refrigeration, every effort should be made to reduce the level of ventilation. Such reductions, however, should not violate acceptable air standards for public safety. Rink managers should check with their State Department of Public Safety or similar agency to find what the local standards are and reduce the ventilation in accordance with these standards. Reduced ventilation is especially effective if the exhaust fumes from the Zamboni can be reduced. A reduction in

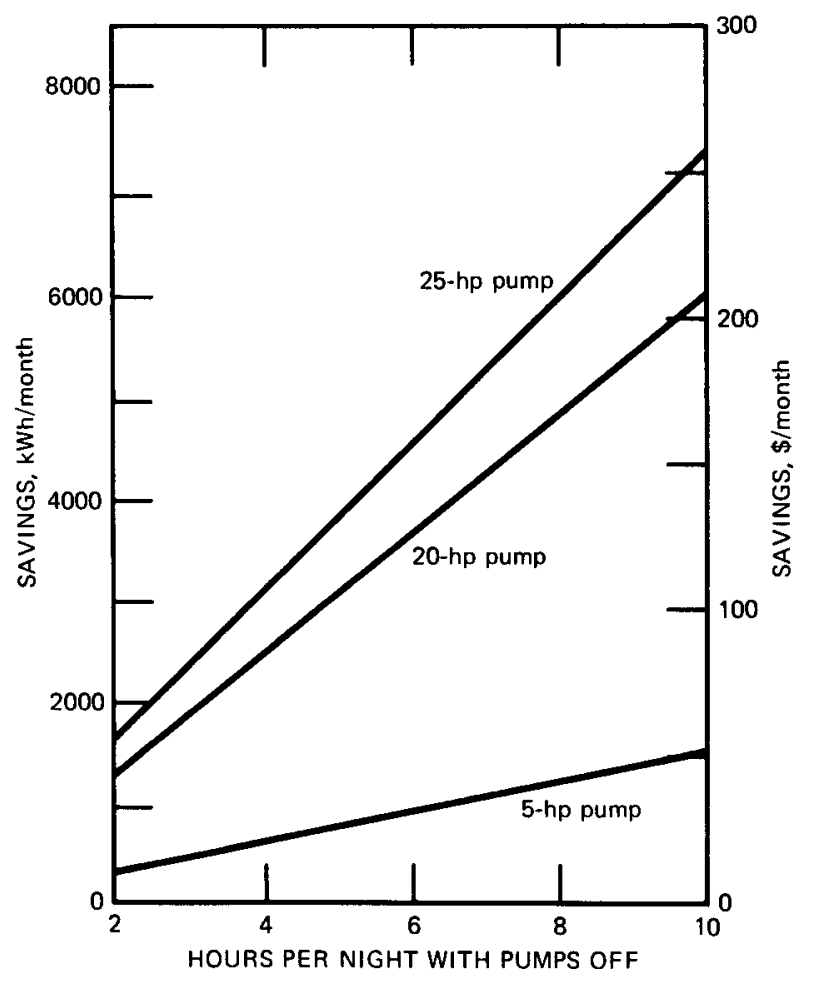

Fig. 4 Savings from shutting pumps off at night. fumes can be accomplished in two ways. First, if the Zamboni is being replaced, a battery-powered electric model should be considered. Second, the gasoline-powered engine of a conventional Zamboni can be converted to burn propane gas. The exhaust from a propane engine is less noxious and toxic than the exhaust from a gasoline engine.

In addition to forced ventilation, warm, humid air also enters the rink through doors and other openings in the rink. If the swinging entrance doors to the rink are blocked open or do not shut tightly because of old or nonexistent weather stripping, a considerable amount of warm, humid air can enter the rink. The conclusion is obvious, but too often neglected. During warm weather the rink manager must be alert to sources of infiltrating air and try to seal the rink as much as possible.

\section{DEHUMIDIFICATION}

Rinks that are open during the late spring, summer, or early fall must have dehumidification or air conditioning equipment to control fogging within the rink and water drip from the ceiling. Most manufacturers of dehumidification equipment recommend that the equipment be set to run automatically to achieve a low relative humidity (about $50 \%$ ) rather than turned on only when fog is evident. However, at least two ice rink consultants regard the automatic setting as a waste of money and recommend that dehumidifiers be used only when necessary.

The reason for the manufacturers' recommendations that dehumidification be used to achieve a low relative humidity is based on the premise that water vapor not removed by the dehumidifier will freeze out on the ice slab surface and this can be costly. A dehumidifier removes water vapor as liquid water, and this process requires $13 \%$ less refrigeration than freezing the water vapor on the ice slab. Also, the compressor of a dehumidifier operates at a suction temperature that is $20^{\circ} \mathrm{F}$ to $30^{\circ} \mathrm{F}$ higher than the suction temperature of the rink compressor, and higher suction temperatures give more efficient refrigeration.

Dehumidifiers are typically $67 \%$ more efficient than direct refrigeration systems and $135 \%$ more efficient than conventional brine refrigeration systems. The combination of the higher efficiency of dehumidifiers and the $13 \%$ lower refrigeration load results in the cost of dehumidification being lowered to $40 \%$ of the cost of allowing the water vapor to freeze out on the ice surface. The ice rink section of the 1978 edition of the American Society of Heating, Refrigerating, and Air-Conditioning Engineers (ASHRAE) Handbook estimates that water vapor in the air accounts for $15 \%$ of the total refrigeration load. Therefore, shifting this refrigeration load to a dehumidifier would save $9 \%$ $(60 \%$ of $15 \%)$ of the total refrigeration load.

There are two major problems with these arguments. First, dehumidified air is usually reheated before it leaves the dehumidifier. The reason for this is that the dehumidi- 
fier works by cooling air to the dew point corresponding to the required relative humidity. This dew point is too cold $\left(40^{\circ} \mathrm{F}\right)$ for the air to be blown directly into the rink. For example, if incoming air at $80^{\circ} \mathrm{F}$ and $90 \%$ relative humidity is to be cooled and dehumidified to $50^{\circ} \mathrm{F}$ and $50 \%$ relative humidity, the temperature of the air must be lowered to $41^{\circ} \mathrm{F}$ to remove the excess moisture and then raised to $50^{\circ} \mathrm{F}$. In reheating the air, $10 \%$ of the refrigeration capacity of the dehumidifier is wasted.

Second, the original premise of the dehumidifier manufacturers that water vapor not removed by dehumidification will freeze out on the ice surface may not be true. The reasoning here is that, with dehumidifiers and ventilating fans turned off, a stratified air system will be built up. That is, hot, humid air will stay in a layer in the upper half of the rink, and cooler, less. humid air, being heavier, will remain in the lower half of the rink. Therefore, there is no reason to remove all the humidity from the air since the water vapor in the warm, humid upper air layer may never reach the ice. The use of a dehumidifier mixes these air layers and brings water vapor to the ice surface, creating a much greater heat load than had the air remained stratified. If this greater heat load outweighs the better efficiency of the dehumidifier, a rink owner would economize by running the dehumidifier only when fogging or ceiling drip is a problem.

The total kilowatt-hour use during successive weeks with the dehumidifiers both on and off at night was measured to see which operating procedure requires less total electric energy. The dehumidifiers were on during the day. Unfortunately, the results were inconclusive. The week-to-week variation in kilowatt-hour use due to changes in weather conditions and rink use was greater than the difference in electric energy use between the weeks with full dehumidification and the weeks with no dehumidification at night. No firm conclusions could be drawn. But it seems that manufacturers may be overstating the energy savings that can be obtained from running dehumidifiers regularly, and there is a good chance that this practice may cost money rather than save it.

\section{ICE THICKNESS}

Letting the ice slab increase in thickness over the season is a sure way of increasing electricity bills. This point cannot be overemphasized. The ice acts as an insulator to prevent heat from being withdrawn by the refrigeration system. If the brine temperature, or compressor suction temperature, is maintained constant, a thicker ice slab will have a higher temperature at the skating surface than a thinner ice slab. Alternately, if the skating surface temperature is to be kept constant, the brine temperature must be reduced as the ice becomes thicker. A quick way of checking ice thickness is to look at the red and blue hockey zone lines.
Lower brine temperatures result in lower efficiencies (a lower COP) for the refrigeration system, and, consequently, the compressor must run more frequently to remove the same amount of heat. Figure 5 shows the relative penalty that is paid by letting the ice thickness increase beyond 0.75 in. As Fig. 5 shows, for every 1-in. increase in ice thickness the energy required to run the compressors increases by $8.4 \%$ in the winter and $14.9 \%$ in the summer. These percent increases are essentially independent of the 0.75 -in. starting thickness, which was arbitrarily selected as an absolute minimum thickness. Although rink owners should keep ice thickness to a minimum, 0.75 in. may be too small for practical operation.

\section{REDUCED LIGHTING}

A very important part of an energy-reduction program is the close control of the number of lights that are used for each rink activity. Any decrease in the amount of lighting over the ice gives a double savings, one for the kilowatthours to run the lights and one for the refrigeration to remove the heat that the lights generate. A reduction of 10 $\mathrm{kW}$ of lighting will reduce your total electric power use by 12 to $14 \mathrm{~kW}$ and save $\$ 240$ to $\$ 290$ per month in kilowatt-hours if the rink is used $16 \mathrm{hr}$ per day.

Substantial savings in lighting are fairly easy to achieve. A bright light-reflecting interior paint will help in reducing lighting costs. State-owned rinks in Massachusetts are painted with bright yellow epoxy paint that reduces maintenance costs as well as lighting costs. Electric energy can be saved by matching the number of lights to the rink activity. Figure skating requires 10 footcandles (a standard unit of light intensity); general skating, 15 footcandles; and hockey, 80 to 100 footcandles. Most rinks, however, have a maximum light intensity of 35 to 50 footcandles; thus only a quarter of the total light intensity is needed for figure skating and only a third for general skating.

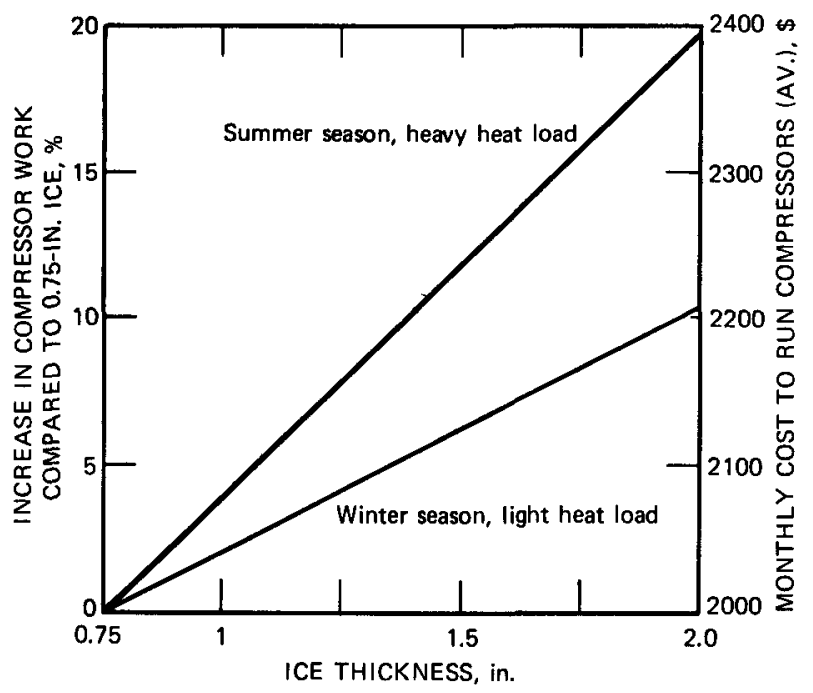

Fig. 5 Variation of compressor work with ice thickness. 
Light intensity is most easily controlled with fluorescent lighting. Rinks with sophisticated low-voltage controls can simply dial the amount of lighting that is necessary. Rinks with conventional fluorescent lighting can best reduce the light intensity by rewiring their lights so that fluorescent bulbs within a lighting fixture (luminaire) can be turned off individually. This reduces the light intensity and, since every fixture is on, still keeps the rink evenly lit.

Light intensity is more difficult to control with mercury and sodium vapor lights. Turning lights on and off decreases the lifetime of the lamps. The shortened lamp lifetime offsets some of the electrical savings from having the lights off. There is a minimum off time that just pays for the decrease in lamp lifetime. This minimum off time is $15 \mathrm{~min}$ for fluorescent lights and $1 \mathrm{hr}$ for mercury and sodium lights. Therefore, for maximum savings a rink with mercury or sodium lights should schedule hockey activities in one block, figure skating in another block, etc., so that the lights are turned on and off as few times as possible.

\section{SUMMARY ON CHANGES IN OPERATING PROCEDURE}

The calculation of how much energy can be conserved by adopting some of the changes in operating procedures discussed in this section is straightforward. For other procedural changes, however, the potential savings are less clear. Included in this category are when to run the ventilation and dehumidification systems, how high to raise the brine temperature, how cold to make the resurfacing water, etc. One way for a rink manager to answer these questions for his own facility is to experiment himself. For example, he could run one week with his dehumidification equipment on and compare the use of electricity to the following week's use when the dehumidification equipment was off. Before running any experiments the rink manager should make sure that they will not substantially alter his electrical demand and therefore be very costly. Clearly some of the recommendations made in this section involve some risk of losing the ice. A rink manager may not wish to accept this risk. If he does he should carefully plan any changes that are made and monitor the results achieved. For example, rather than raise the brine temperature by $2^{\circ} \mathrm{F}$ at once, he should start with $1^{\circ} \mathrm{F}$ and see what happens. One last suggestion that can be made is to bring rink employees into the game plan of saving energy. Let them know what is being done and perhaps reward them with a bonus or time off for their energy conservation ideas, if they prove fruitful. 


\section{Chapter $3 \quad$ Moderate Investments}

\section{SNOW MELTING}

Many rinks in urban areas do not have a convenient place to dump the snow that is scraped off during resurfacing. These rinks must resort to melting the snow to dispose of it. Snow melting is normally done in a pit with a hot-water spray, and this requires large amounts of water as well as energy to heat the water. Table 2 itemizes the costs per month for snow melting based on the following assumptions:

- Snow equivalent to $140 \mathrm{gal}$ of water is removed per resurfacing.

- Resurfacing is done eight times per day.

- A $70 \%$ efficient gas water heater is used to heat the water.

- The hot water from the gas heater has a temperature of $160^{\circ} \mathrm{F}$.

- The cold water to the gas heater has a temperature of $60^{\circ} \mathrm{F}$.

- The temperature of the water drained from the snow pit is $50^{\circ} \mathrm{F}$.

The costs itemized in Table 2 can be eliminated with a snow-melting kit marketed by several ice rink and refrigeration equipment manufacturers. These kits cost approximately $\$ 2600$ installed, and they run automatically. Hot refrigerant gas from the compressor is used to heat water, which in turn is pumped to a heating coil in the snow-melting pit. A diagram of the system is shown in Fig. 6.

Operating costs for the system are negligible (estimated at $\$ 7.50 /$ month) since only a 1 -hp pump is needed to pump the hot water through the pit. The payout times for the snow-melting systems vary from 12 to 30 calendar months depending on the length of the skating season. The payout times are summarized in Fig. 7 for the assumptions listed above.

\section{PREHEATING HOT WATER}

With essentially the same waste heat recovery system discussed above for melting snow, water for use in the Zamboni, for showers, etc., can be preheated. For preheating water, the snow pit in Fig. 6 is replaced with a hot-water storage tank. The Wissahickon Skating Club in Philadelphia has such a system. They preheat their water to approximately $100^{\circ} \mathrm{F}$ with a system that cost $\$ 6000$. Although this cost exceeds the specification of moderate investment, $\$ 3000$, the water preheater is discussed in this section because of its similarity to the snow-melting kit.
The $100^{\circ} \mathrm{F}$ water is raised to the desired final temperature by conventional heating. The Wissahickon facility saving for 12-month operation is estimated as 2000 gal of heating oil, and the payout time is a little over 3 years. Preheating hot water will be most favorable for rinks that are open year round. Rinks that heat their water with electric heat also should find this option even more attractive.

\section{POWER FACTOR IMPROVEMENT}

Compressors, dehumidifiers, pumps, and other equipment with electric motors have a current phase lag within their motors which can result in higher electric demand (kilowatt) charges and somewhat higher electric energy (kilowatt-hour) use. A current phase lag occurs when the electric voltage peaks before the peak in the electric current. This phase lag is measured by the power factor. A power factor of 1 corresponds to no phase lag, and a power factor of zero corresponds to maximum phase lag. Sometimes power factors are expressed in percents; so a power factor of 0.80 is also referred to as a power factor of $80 \%$.

Power factors can be increased by installing industrial capacitors at the main electrical switchboard in a rink. The capacitors are small and require no maintenance. Furthermore, the installed cost of the capacitors is small $(\$ 500$ to $\$ 1500)$.

Table 2 Costs of Snow Melting per Month

\begin{tabular}{ll} 
Water required to melt snow, gal & 49,500 \\
Energy required to melt snow, $10^{6}$ Btu & 69 \\
Cost of gas, $\$$ & 188 \\
Cost of water and sewer, $\$$ & 36 \\
\hline
\end{tabular}

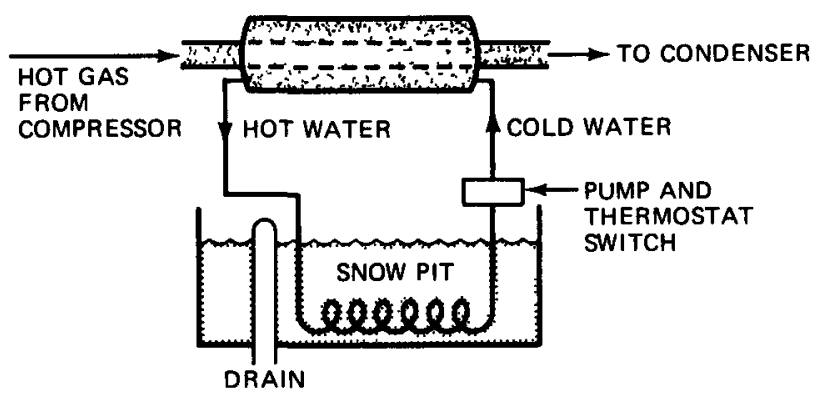

Fig. 6 Snow-mel ting pit and heating system. 
The savings from an increased power factor come from a decrease in electric energy use and in some cases a decrease in electric demand billing as well. The electric energy savings result from lower heat losses within the motor windings. For each increase of 0.1 in power factor, the kilowatt-hours used by all motors in the rink (essentially all electrical energy use except lights) will be reduced by $0.6 \%$. Typical ice rink power factors are between 0.70 and 0.85 and can be raised to $\mathbf{0 . 9 5}$. Therefore, ice rinks can expect to reduce their kilowatt-hour use by $1 \%$ to $2 \%$ by increasing their power factor.

Whether or not the electrical demand is reduced depends on the utility rate schedule for the rink. One type of rate schedule bills the rink for the actual kilowatts of power used, assuming a fixed power factor. Typically, the power factor of a rink is assumed to be 0.80 by utility companies. No demand savings are available to a rink under
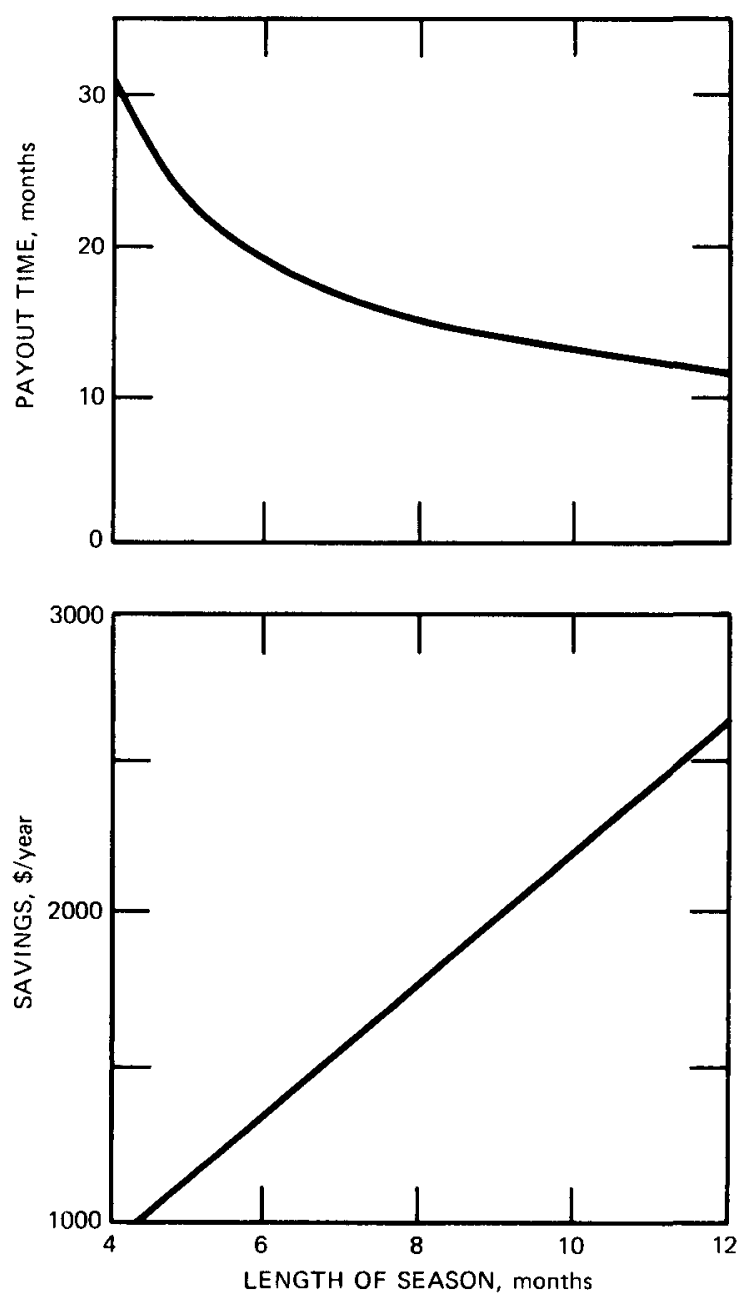

Fig. 7 Yearly savings and payout time for snow-melting kit. this schedule, even if their power factor is increased. This rate schedule is referred to as "utility option." Figure 8 shows the payout times for industrial capacitors for rinks with both the "utility option" and a "consumer option" (described below).

A second type of rate schedule (referred to as consumer option) sometimes applies to ice rinks. With this type schedule, the utility company assumes that its customers have a power factor of 0.80 (sometimes 0.85 ), but the power consumer has the right to a reduced demand billing if he raises his power factor above 0.80 . For example, if the rink power factor is raised to 0.95 , then the electric demand billing is reduced by the fraction $0.80 / 0.95$. Therefore, a rink that uses $200 \mathrm{~kW}$ of power would be billed for only $200 \times 0.80 / 0.95$ or $168 \mathrm{~kW}$ of power.

As Fig. 8 shows, the payout times are much shorter for the consumer option. However, even for the utility option rate schedule, the payout times are attractive. The exact savings and payout time will vary with the original power factor, local rate schedule for both kilowatt demand and energy, and the line voltage to the rink. Therefore, the rink manager should talk to a utility representative to find the optimum capacitor size for his rink and the expected savings. The rink manager could also contact a representative of an industrial capacitor manufacturer. Most manufacturers will have an engineer write a free appraisal of a rink's requirements.

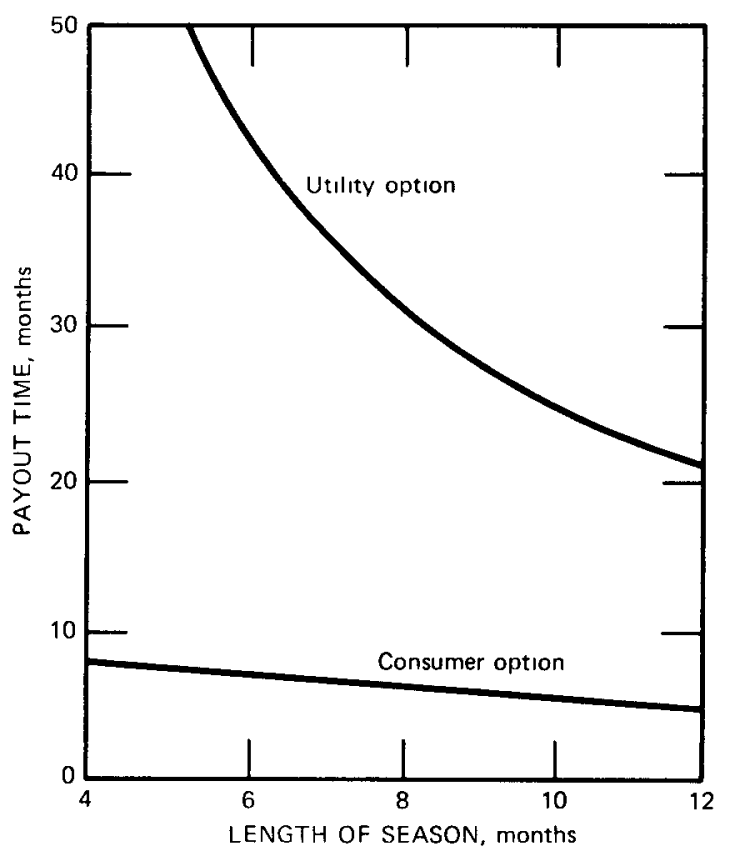

Fig. 8 Payout time for capacitors. 


\section{Chapter 4}

\section{Major Investments}

\section{NONRADIATIVE CEILINGS}

Infrared radiation from the ceiling to the ice, a major heat load in all ice rinks, amounts to $25 \%$ to $30 \%$ of the heat load during the day and an even higher percentage at night. Since infrared radiation is invisible, its importance in ice rinks is easy to ignore. However, the fact that infrared radiation can be a major source of heat is evidenced by its use in heat lamps. The infrared radiation from an ice rink ceiling, of course, is much less intense than that from a heat lamp and cannot be felt by a person in the arena; nevertheless, the amount of heat radiated to the ice is substantial. Fortunately, infrared radiation is one source of heat that can be nearly totally eliminated.

The amount of heat radiated to the ice is controlled by the temperatures of the ceiling and of the ice surface and by a proportionality factor called emissivity. Emissivity is a property of the radiating material; it is 1 for a perfect radiator of heat and 0 for a material that radiates no heat. The most desirable ceiling for an ice rink would be one whose surface has zero emissivity. Common ceiling materials, such as wood and ordinary paints and varnishes, however, have emissivities between 0.85 and 0.95 .

The only practical way to reduce the amount of heat radiated from a ceiling is to change the emissivity of the ceiling. Emissivity can be changed in two ways: (1) by painting the ceiling with a special aluminum-based lowemissivity paint or by installing a polished aluminum-foilfaced false ceiling. The false ceiling has a lower emissivity (0.04) than does the paint $(0.24)$ and shows the greater savings in refrigeration costs. The false ceiling is also more pleasing to the eye than a ceiling painted with an aluminum-based paint.

The actual savings from a nonradiating false ceiling have been substantiated in at least two rinks that have kept detailed records of kilowatt-hour use. Figure 9 shows the electrical kWh $\log$ for the Wissahickon Skating Club in Philadelphia. The rink was shut down for differing numbers of weeks during May and June; consequently the kilowatthour use during these two months is not shown. The total reduction in $\mathrm{kWh}$ use was $26 \%$. The University of Delaware claims even greater savings at their rink, having recorded a $30 \%$ decrease in $\mathrm{kWh}$ use in the year following the installation of a false ceiling.

There are substantial savings available from an aluminum false ceiling in addition to a reduced refrigeration load. The manager of the Wissahickon ice rink was able to reduce his lighting by one-third because the aluminum ceiling reflected more light to the rink. The reduced lighting and refrigeration use cut his electric kilowatt demand by an average of $15 \mathrm{~kW} /$ month. Also, the heat that is no longer radiated to the ice stays in the ceiling and raises the temperature of the ceiling by an estimated $10^{\circ} \mathrm{F}$ to $15^{\circ} \mathrm{F}$. A higher ceiling temperature will keep the ceiling dryer if air can circulate in the space between the false ceiling and the original ceiling. If air circulation is cut off above the false ceiling, a problem can arise. This is discussed later. With a dryer ceiling, space heating can be cut significantly. The University of Delaware reported that the amount of gas used for space heating was reduced by $30 \%$ following installation of the false ceiling.

The monthly saving for an individual rink depends on many variables, e.g., the type of refrigeration system used, the geographical location of the rink, the season of the year, and the shape of the ceiling. Figure 10 shows how the estimated savings in refrigeration vary with ceiling temperature for a 200- by 85-ft rink with a 20-ft-high (at edge) shallow peaked ceiling, shown in Fig. 11. Rinks with 40 -ft-high curved ceilings will have savings about $10 \%$ greater owing to the increased area for radiation and the focusing effect of the shape of the roof. In Fig. 10, the savings for the direct refrigeration system are less than those for the brine system because the direct refrigeration system is more energy efficient. Since the direct refrigeration system uses less energy, there is less energy to save.

The installed cost of a false ceiling was $\$ 29,000$ in 1978. The cost of the low-emissivity paint to cover the ceiling of a 200 - by $85-\mathrm{ft}$ rink was $\$ 2400$, and the estimated labor cost was $\$ 9600$ ( $4 \times$ cost of paint) in 1978. The

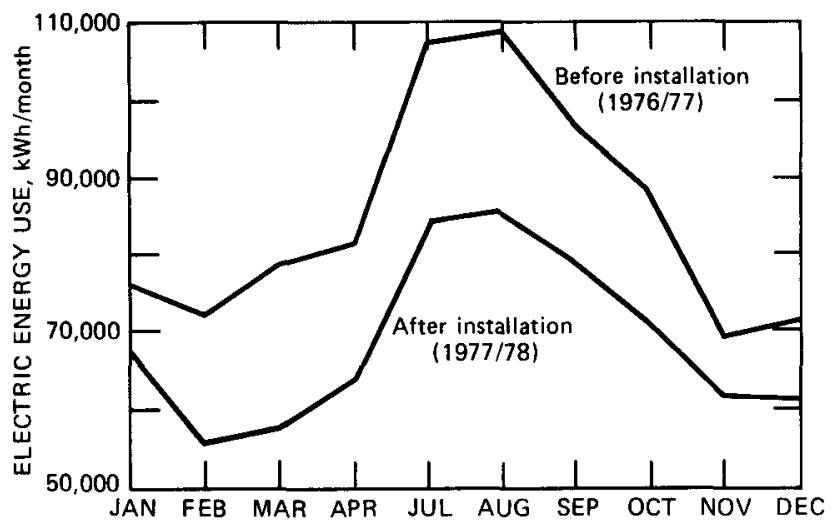

Fig. 9 Kilowatt-hour savings resulting from the installation of an aluminum false ceiling. 
"painted ceiling could need repainting every 4 to 5 vears; the resulting high yearly depreciation therefore would make the false ceiling a better investment, especially if the rink is open less than 11 months. Rink managers who are considering using the low-emissivity paint should check with the manufacturer on how often ceilings in rinks that have used the paint have had to be repainted or cleaned. Firm quotations on labor costs should also be obtained.

The payout time for the false ceiling is shown in Fig. 12. In the calculation of payout times for the northern rink, ceiling temperatures of $50^{\circ} \mathrm{F}, 60^{\circ} \mathrm{F}$, and $70^{\circ} \mathrm{F}$ were used for 5, 4, and 3 months, respectively (see App. 4). For southern rinks, ceiling temperatures of $60^{\circ} \mathrm{F}, 70^{\circ} \mathrm{F}$, and $80^{\circ} \mathrm{F}$ were used. A lighting credit of $4 \mathrm{~kW}$ was assumed for both rinks, and for northern rinks $25 \%$ of the average Massachusetts gas bill of $\$ 14,000$ was credited to the yearly savings. It was assumed that no space heating was needed for southern rinks.

Only two problems with false ceilings have been reported; both were easily corrected. In one rink, the aluminum foil was faced on fiberboard, and hockey pucks had punched holes in the ceiling. Rinks with the aluminum ioil faced on fiberglass or other more rigid material have not had this problem. Second, the false ceiling should not extend over the entire ceiling area. Doing so creates a stagnant air layer between the false ceiling and the actual ceiling. With no air circulation, water vapor condenses from the air onto the upper, colder ceiling. This water can drip down onto the false ceiling and collect in the panels. It is possible that the panels might become so waterlogged that the ceiling would collapse. Leaving a gap of $5 \mathrm{ft}$ to $10 \mathrm{ft}$ around the edge of the false ceiling for air circulation will prevent this condensation.

Radiation is largely directed straight down from the ceiling. Relatively little radiation comes off the ceiling at an angle. Therefore, since the gap along the edge of the false ceiling would be directly over the aisles rather than over the ice, it will hardly affect the refrigeration savings. In addition, since radiation only travels in straight lines, the small fraction of the radiation that is angled through the gap toward the ice is in large part blocked by the top of the false ceiling and by the dashers. Besides helping to prevent moisture buildup above the false ceiling, a 10-ft gap along the edge of the ceiling reduces the area of the false ceiling (and cost) by $25 \%$.

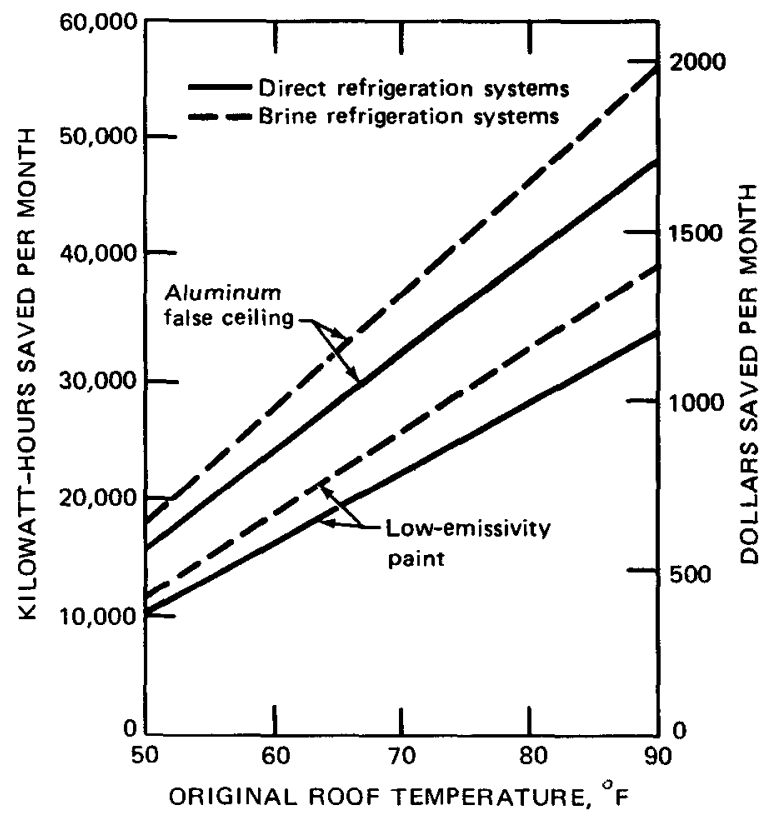

Fig. 10 Savings from installing a false ceiling or using lowemissivity paint on the ceiling.

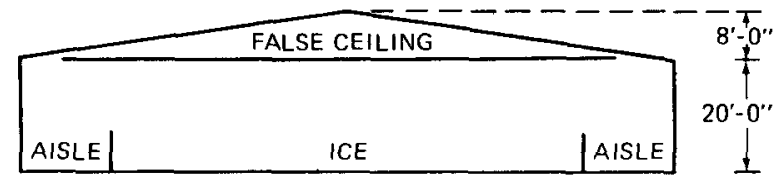

Fig. 11 Diagram of a false ceiling installation.

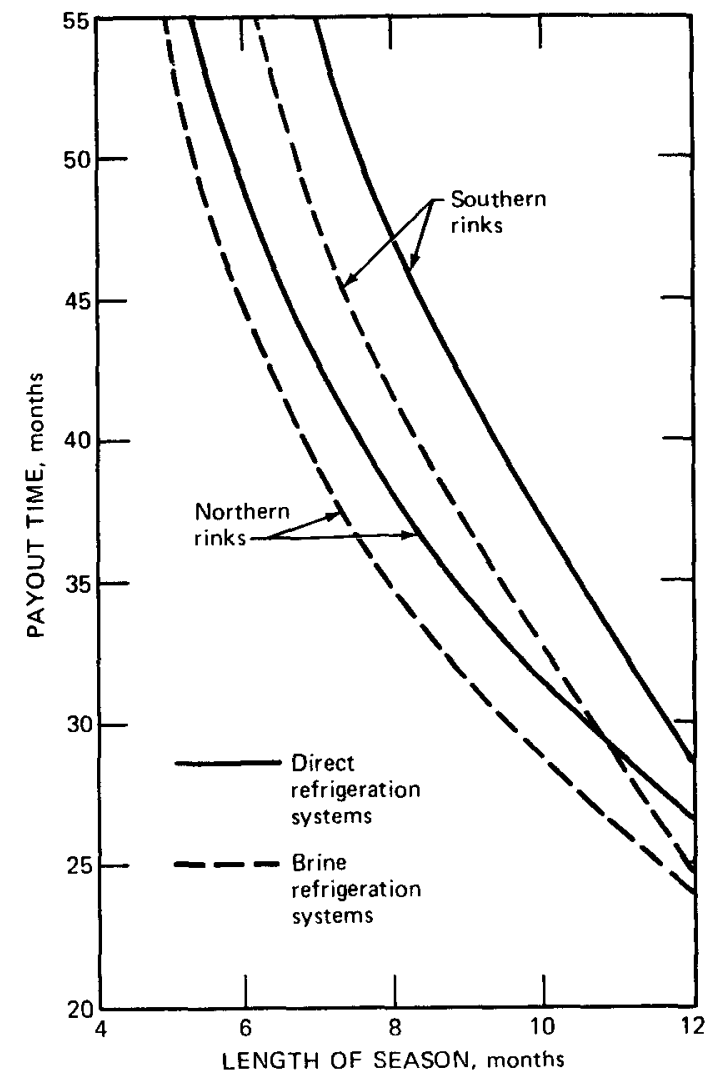

Fig. 12 Payout time for a false ceiling. 


\section{ELECTRONIC LOAD CONTROL}

Modern solid state electronic controllers are now being used in many rinks to cut refrigeration and air conditıonıng costs. The electronic controllers operate in two distınct ways. The first method, load shedding, controls the maxımum kılowatt load (kW) and reduces electrical demand charges The second method, load cyclıng, reduces energy charges (kWh) as well as demand charges (kW) by reducıng the tıme that each pıece of equipment is runnıng. This reduction is possible because most ice rinks are overdesigned and have more capacity (refrigeration, pumping, and dehumidification) than is needed

In load shedding the controller monitors the electric load 100 tımes durıng the electrical demand measurıng period (approximately every $10 \mathrm{sec}$ ) and shuts down nonessential or deferable equipment if the total kılowatt load exceed's a target demand The deferable load is the electric power load attributable to equipment that can be shut down for short periods of time without detriment to the rınk, eg, water heaters, ventılation fans, electrıc heaters, dehumidifiers, air conditioners, cooling tower fans, and pumps These items would automatically shut down for a brief period while the main compressor is fully loaded or the auxiliary compressor is running The order in which the deferable equipment is shut down can be specified by the rınk manager Overrıde switches can be installed in the manager's office to permit him to turn equipment on regardless of the electrical demand These override switches keep total control of the ice quality in the hands of the rink manager

At Orr Rınk in Amherst, the deferable load accounts for $9 \%$ of the maxımum normal operatıng load of $214 \mathrm{~kW}$, excluding lights Therefore, the savings in electrical demand could amount to $19 \mathrm{~kW}$ or $\$ 67$ per month The cost of a load-shedding controller is about $\$ 3000$ The payout tıme therefore would be 45 months for year round operation or 107 months for the actual 5-month season at Orr Rınk This payout time is rather long, and most rinks will want to consider the load-cycling controller A load cyclıng con troller is generally a much better investment

Load cycling, the second method of load control, uses a preset on/off cycle for each electrical unit or group of units. Kilowatt demand is automatically controlled by the cycle program, which specifies which pieces of equipment are on at any given tıme $A$ load-cycling controller reduces kılowatt hours as well as electrical demand The kilowatt hour savings result from shuttıng down individual pıeces of equipment for predetermıned periods of tıme For example, brine pumps can be turned off for short periods of time rather than being run contınuousiy, hot water heaters can be shut off at night, compressors can be run less often or shut down at night

How much money and energy can be saved with load cyclıng controllers? One manufacturer estımates energy savings at a conservative $10 \%$ of the kılowatt hours used by the controlled equipment Electric bills from a New York $\mathrm{C}$ try supermarket show $12 \%$ savings in both electrical demand and energy costs, and a Massachusetts discount store reports savings of $15 \%$ for the first year of operation. A load-cycling controller was installed in the Batavia, New York, munıcıpal rınk in 1978, the Assıstant Engıneer for the city estımates that they are savıng $\$ 600$ to $\$ 700$ per month.

A load cycling controller was installed at the Fall River, Massachusetts, rink in 1977 Figure 13 shows the kılowatt-hour use for the first year after installation compared to the average electrical energy use for the previous two years The total energy savings for the first year was $152,000 \mathrm{kWh}$ or $17 \%$

The controller at Fall River was disconnected in September during start-up because its use would have prolonged the tıme it took to make ice Disconnecting the controller during this period of maximum power demand, however, elımınated most of the kilowatt demand savings for the entire year since a ratchet clause in the demand rate schedule kept the demand billıng from droppıng durıng periods of lesser power use As a result, the savings in demand at Fall River were only $4 \%$ instead of the antıcıpated $10 \%$

An ımportant aspect of Installıng a load cycling controller is the design of the on/off sequences These sequences should be designed by someone who is knowledgeable about running an ice rink At an installation in Georgia, the dehumidification equipment was programmed to be on for too short a tıme Consequently, the air became too humid, and the ceiling tiles became waterlogged and eventually collapsed A change in the

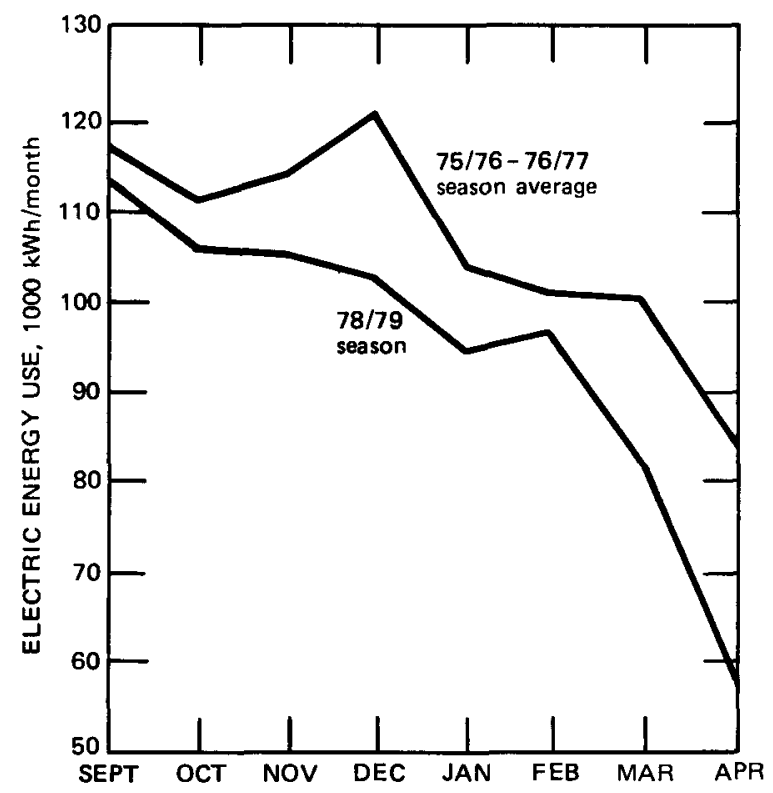

Fig. 13 Electric energy use before and after installation of a load-cycling controller 
- program of the controller, as recommended by an ice rink consultant, easily solved the humidity problem.

The dollar returns with the load-cycling controller are very attractive, provided the controller is properly programmed. The installed cost of the load-cycling system at Fall River was $\$ 8274$; the actual savings for the first year were $\$ 698$ per month; the payout time was 17 calendar months for an 8-month season. Figure 14 shows the payout times for skating seasons of various lengths. The payout times and savings for the load-cycling controller are superior to those for the load-averaging controller, and the return on investment is so large that even rinks with short seasons should find it profitable to install a load-cycling controller. Rink managers should get bids from several companies on load controllers. Some companies will even guarantee a minimum percentage savings in utility costs.

\section{NEW LIGHTING SYSTEMS}

Most new skating rinks install either a high-pressure sodium or a fluorescent lighting system rather than the mercury lighting found in most older rinks. The newer systems offer significant savings in electric energy and fluorescent lighting offers increased flexibility in controlling light intensity. Table 3 lists the efficiencies and the operating costs of these three lighting systems.

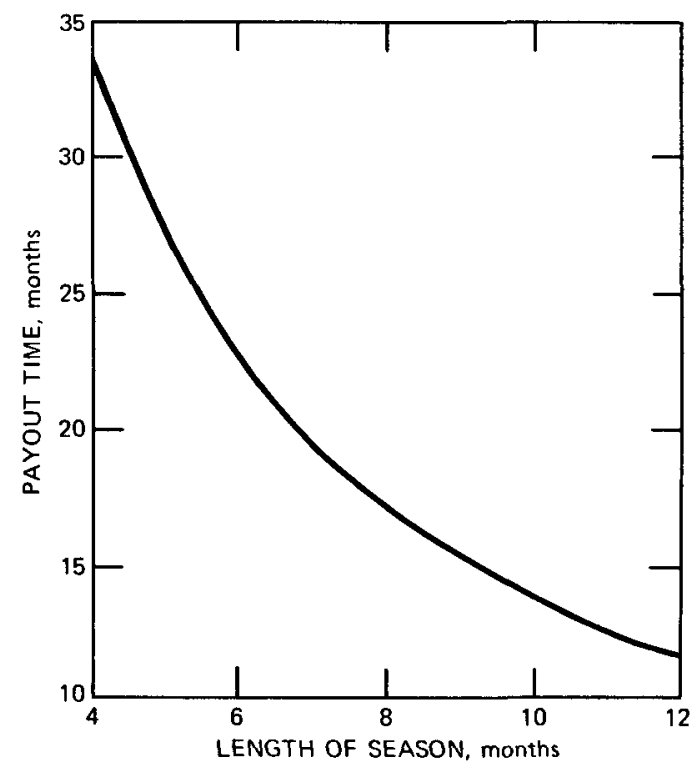

Fig. 14 Payout time for a load-cycling controller.

Table 3 Lighting System Efficiency and Operating Costs

\begin{tabular}{lccc}
\hline & $\begin{array}{c}\text { High-pressure } \\
\text { sodium }\end{array}$ & Fluorescent & Mercury \\
\hline Efficiency, lumens/watt & 125 & 71 & 46 \\
Cost per month, \$ & 365 & 642 & 953 \\
\hline
\end{tabular}

In Table 3 the unit lumens/watt measures the amount of light produced per kilowatt of electric power. The cost per month is the cost to provide $\mathbf{5 5}$ footcandles of light (hockey-level light intensity) at ice level for a 200-ft by 85-ft rink operating for an 18-hr day. The cost per month includes lamp replacement costs as well as electrical costs. The choice between installing high-pressure sodium and fluorescent systems depends on the major uses of the rink. For rinks with hockey as a major use, a high light intensity (35 to 100 footcandles) is necessary. For these rinks a high-pressure sodium system would be of greatest benefit because of its high efficiency.

Several academies in New England have recently installed high-pressure sodium lighting, and the Williston Academy in Easthampton, Massachusetts, has replaced its mercury lights with high-pressure sodium lights to increase the light intensity by $40 \%$ and save money at the same time. A consulting report for the Williston rink estimates that, even with the higher light intensity, the electrical cost will be reduced by $\$ 2380$ for the 8 -month season. The total annual savings are even higher ( $\$ 2550 /$ year) because of lower lamp replacement and maintenance costs. The installed cost of the new lighting system is estimated at $\$ 7800$, excluding the initial lamp cost. The payout time is 35 calendar months. The consulting report for Williston did not include any savings in refrigeration due to the decrease in heat generated by the lamps. If half the heat generated by the lighting system is removed by the refrigeration system, the payout time would be reduced to 30 months. Also, if the light intensity had been kept at 39 footcandles rather than increased to 55 footcandles, the payout time would have been reduced to 20 months.

Rinks that have a variety of uses, such as municipal rinks, often choose fluorescent lights rather than high-pressure sodium lights. For these rinks much of the ice time is used for patch skating and general skating, for which the light intensity is much lower (10 to 15 footcandles) than that necessary for hockey (35 to 100 footcandles). Thus, the higher efficiency of high-pressure sodium lights is less important.

High-pressure sodium lights, like mercury lights, provide an uneven light intensity when most of the lamps are turned off for patch skating. There can also be soft spots in the ice directly under sodium or mercury lamps owing to radiation from the lamps. Sodium lamps have a very slight amber coloration, which does not appear to detract from their use in rinks. Fluorescent lighting provides an even light intensity over the entire rink, even at low light levels, eliminating shadows and warm spots. In addition, fluorescent lights can profitably be turned off for periods as short as $\mathbf{1 5} \mathrm{min}$ to take advantage of short periods of time when the rink is unused. Both mercury and high-pressure sodium lights should not be turned on and off more frequently than once an hour, since the cost of the resulting 
decrease in lamp life will exceed the energy savings. Therefore, fluorescent lighting provides a highly flexible system in which the light intensity can be closely controlled according to the rink use, with significant savings.

The payout time for fluorescent lighting is difficult to judge accurately since a large proportion of the savings results from being able to turn down the lights for short periods of time. However, if it is assumed that with fluorescent lighting $40 \%$ of the ice time is at full intensity and $60 \%$ is at one-fourth intensity (compared to $50 \%$ each with mercury lighting), the payout time for a fluorescent lighting system is 33 months for year-round operation. Figure 15 summarizes the payout times for a change from mercury lights with an intensity of 55 footcandles to high-pressure sodium and fluorescent lights for various rink conditions. The curves in Fig. 15 include an energy credit for reduced refrigeration resulting from reduced lighting (see App. 4).

In summary, high-pressure sodium lights are the least expensive to run and should be considered for rinks that are open for less than 10 months or for rinks that are used primarily for hockey. Fluorescent systems can be considered for rinks that are open most of the year and

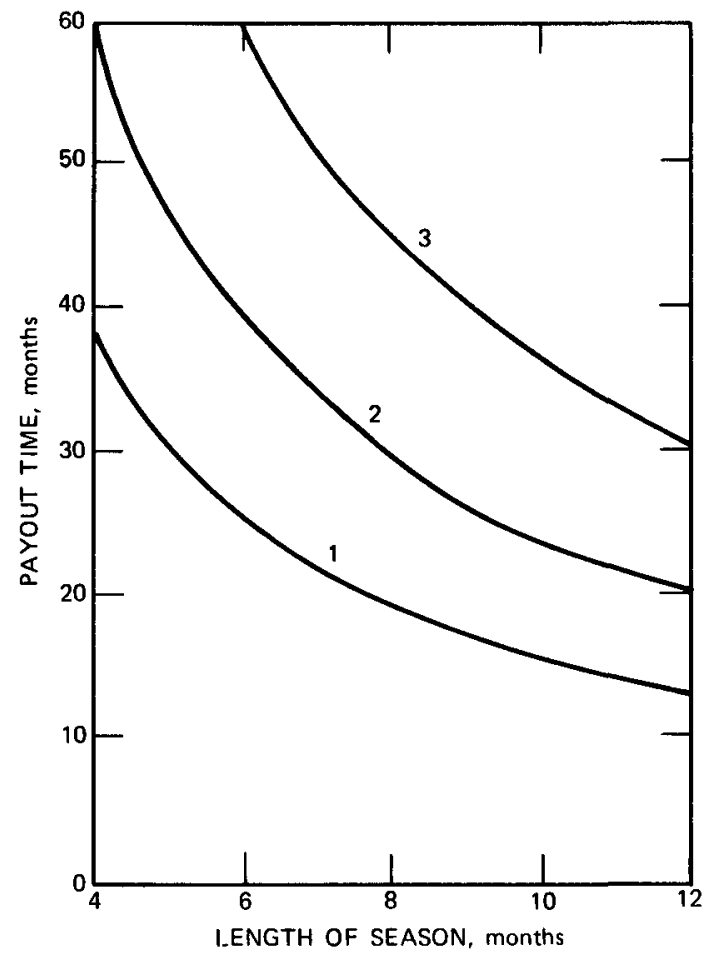

Fig. 15 Payout time for new lighting systems. (1) High-pressure sodium at 55 footcandles (hockey) for $16 \mathrm{hr}$ per day. (2) High-pressure sodium lights at 55 footcandles for $8 \mathrm{hr}$ per day and at 15 footcandles (general skating) for $8 \mathrm{hr}$ per day. (3) Fluorescent lights at 55 footcandles for $6 \mathrm{hr}$ per day and 15 footcandles for 10 hr per day. have a variety of uses which demands more flexibility in. lighting control and more-even light intensity.

\section{REDUCING SPACE HEATING COSTS WITH CONDENSER WASTE HEAT}

It is ironic that heating should be a major expense in an ice rink (approximately one-half as expensive as the electricity to run a rink). But, costly as it may be, space heating is generally needed both to increase the comfort of the rink patrons and to keep the ceiling dry. The important questions are: How much space heating is necessary? Where should the heat be directed? How can the cost of space heating be minimized?

If the ceiling can be kept dry by means other than by blowing hot air over it, the cost of space heating can be reduced significantly. Installing a nonradiating false ceiling or using dehumidifiers can help maintain a dry ceiling. Potential problems with dehumidification were discussed in Chap. 2. Once a dry ceiling is attained, the space heating can be reduced to the level necessary for the comfort of the spectators in the rink. It is also possible to redirect some of the heated air toward the spectators rather than toward the ceiling. As mentioned previously, the University of Delaware was able to reduce its gas use by $30 \%$ following the installation of an aluminum-faced false ceiling.

The savings on space heating do not stop with reducing the heat. The waste heat rejected in the condenser of the refrigeration system can be a source of most, if not all, the heat needed to keep a rink comfortably warm. Two questions often asked about heat-reclamation systems are: How much heat is available from the condenser? Will it be sufficient to heat the rink in the winter when the space-heating load is greatest and the refrigeration load is least? The amount of available waste heat [measured in hundred standard cubic feet (cct) of natural gas] can be estimated from the formula

$$
\text { Gas savings, } c c f=(k W h \text { used }) \times(A) \times(0.026)
$$

where $A$ is an efficiency factor that depends on the type of refrigeration system (see Table 4). The equation assumes that $75 \%$ of the total kilowatt-hours used by a rink are required to run the refrigeration system, including pumps and fans.

Table 4 Refrigeration System Efficiency Factors (A)

\begin{tabular}{ll}
\hline Refrigeration system & A \\
\hline Conventional Freon/brine & 3.2 \\
Plastic mat Freon/brine & 3.6 \\
Direct Freon refrigeration & 4.2 \\
Conventional ammonia/brine & 3.7 \\
\hline
\end{tabular}


As an example of the estimated gas savings, the North Adams, Massachusetts, rink used $160,000 \mathrm{kWh}$ of electricity and 12,200 ccf of gas in January and February of 1978. North Adams has a conventional Freon/brine system. Therefore, the $160,000 \mathrm{kWh}$ is equivalent to $160,000 \times 3.2 \times 0.026$ or $13,300 \mathrm{ccf}$ of gas, more than was actually used for the two coldest months of the year. On days that are much colder than the January-February average, however, supplemental heating would still be necessary. A conservative estimate of the savings available in waste heat from the condenser is that $75 \%$ of the space-heating needs in Massachusetts rinks could be met with reclaimed heat, giving a savings of $\$ 10,000$ per season.

Can savings of $\$ 10,000$ really be obtained? At the Bloomington Ice Arena in Minnesota, a heat-reclaiming system was installed in 1977. This system pumped hot Freon from the compressor to a fan-and-fin heat exchanger (similar to an automobile radiator) located inside the heating duct within the rink. A bypass valve led to an evaporative water condenser in case additional cooling was necessary for the Freon. The evaporative condenser was not used during the winter heating season, which eliminated the worrisome problem of condenser freeze-up during winter.

The Bloomington rink is a dual rink, and, even during the coldest days of the Minnesota winter, the heat from the refrigeration system was all that was needed to heat one of the two rinks. (It should be noted that the intent at the Bloomington facility was to recover only enough heat to heat one rink. More heat could have been recovered.) It is estimated that the reclamation system saved $\$ 8000$ to $\$ 10,000$ during the first full season of operation. The cost of the installed waste-heat-reclamation system was $\$ 21,000$ in 1977, and this gave a very attractive payout time of 28 calendar months. A 1979 consulting report for the stateowned rinks in Massachusetts estimates that waste-heat recovery is feasible for space heating and the payout time for it is 1.9 years.

A point about rinks that are not heated should be made here. Studies on Orr Rink in Amherst, Massachusetts, show that, for every Btu put into the rink through space heating, the load on the refrigeration system is increased by approximately $1 \mathrm{Btu}$. On the order of $60 \%$ of the load on the refrigeration system can be attributed to space heating. The most energy efficient way to run a rink is not to heat it provided that condensation, freezing of water pipes, and other problems do not arise. Patron comfort also must be considered. If waste heat is reclaimed to heat a previously unheated rink, the additional operating costs for the refrigeration system become significant. For a conventional Freon/brine system, the additional operating costs can be estimated as $\$ 15,500$ per season. The assumptions involved in this estimate are that the rink would have a gas heating bill of $\$ 14,000$ per season, the average for Massachusetts, and that each Btu added as heat increases the refrigeration load by $1 \mathrm{Btu}$. The estimated additional heating costs for a direct refrigeration and ammonia/brine system would be 15 to $20 \%$ less than those for the Freon/brine system, and those for the plastic-mat system would be about the same, $\$ 15,500$. The total costs for heating a previously unheated rink with waste heat would be $\$ 15,500$ per season plus a one time cost of approximately $\$ 22,000$. Given these high costs, a rink manager should consider whether it is worth it to add heat to an unheated rink. 


\section{Glossary and Abbreviations}

Brine: $A$ term used in the ice rink industry to refer to either a real brine solution (salt water) or glycol.

British thermal unit: A standard unit of heat (1 Btu is the amount of heat needed to raise the temperature of 1 lb of water by $1^{\circ} \mathrm{F}$ ). For comparison, 100 standard cubic feet (1 ccf) of gas produces about 100,000 Btu of heat, and $1 \mathrm{kWh}$ of electricity, if converted to heat, would produce $3412 \mathrm{Btu}$.

Coefficient of performance: The ratio of heat extracted by a refrigeration system to the work necessary to run the system. Both heat and work must be in the same units. A higher coefficient of performance means a more efficient refrigeration system.

Convective heat transfer: The transfer of heat out of or into a moving gas or liquid stream due to a difference in temperature.

Convective mass transfer: The transfer of mass (e.g., water vapor) out of or into a moving gas or liquid stream. There will normally be a latent heat effect associated with convective mass transfer. For example, water vapor freezing onto the ice slab creates a heat load of 1244 Btu per pound of ice formed.

Convective heat load: The heat load due to both convective heat transfer and convective mass transfer.

Dew point: The temperature at which the water vapor in air begins to condense into liquid water.
Direct refrigeration: $A$ refrigeration system in which the brine and the brine heat exchanger (chiller) are eliminated. Cold Freon is pumped directly under the ice, instead of cold brine.

Electric demand or kilowatt demand: The maximum amount of electric power (measured in kilowatts) that is used by a rink.

Emissivity: A measure of how effective a material is in radiating heat. The emissivity is the ratio of the actual heat radiated per unit area by a given material to the amount of heat emitted by a perfect radiator.

Footcandle: A measure of light intensity or brightness.

Infrared radiation: Invisible heat rays that are similar in nature to visible light but lower in energy than visible light.

Lumen per watt: A measure of the efficiency of a lighting system. A lumen per watt measures how much light power is produced per unit of electric power.

Payout time: The time in months necessary for savings realized to pay for equipment and its installation.

Power factor: A measure of the extra generating capacity that an electric utility needs to make up for electric current phase lag. The power factor is equal to the cosine of the current phase lag and is also equal to the ratio (kilowatts)/(kilovolts $x$ amperes).

$\begin{array}{llll}\text { Btu } & \text { British thermal unit } & \text { hp } & \text { horse power } \\ \text { ccf } & \text { hundred cubic feet } & \text { in. } & \text { inches } \\ \text { COP } & \text { coefficient of performance } & \mathrm{kW} & \text { kilowatt } \\ \mathrm{ft} & \text { feet } & \mathrm{kWh} & \text { kilowatt-hour } \\ { }^{\circ} \mathrm{F} & \text { degree Fahrenheit } & \mathrm{mph} & \text { miles per hour }\end{array}$




\section{Appendix 1 Adjustment of Savings and Payout Times to Account for Varying Utility Rates and Interest}

The payout times and savings calculated for the examples in this manual are based on electric costs of $\$ 0.035 / \mathrm{kWh}$, electric demand costs of $\$ 3.50 / \mathrm{kW}$, and gas costs of $\$ 0.32 /$ ccf. If local utility rates differ from those used for the base case examples, the savings and payout times for a rınk will have to be adjusted to account for the difference in rates. Although the calculated savings and payout times for some of the suggested modifications depend on more than one utılity rate, one utılity usually provides the bulk of the savings. Table 5 lists the modifications suggested in this manual according to the utility cost that is the major factor affecting savings Figures 16 and 17 can be used with Table 5 to find the local payout time and savings of modifications. For example, suppose a rınk was interested In buying a snow-melting kit If the rink had an 8-month season, the base case payout tıme and savings from Fig. 7 would be 15 calendar months and $\$ 1750 /$ year, respectively. Table 5 shows that the major utility cost affecting a snow-melting kit would be the cost of gas, assuming the rink had a gas hot water heater rather than an electric or oll-fired hot water heater. If the local cost of gas is $\$ 0.37 / \mathrm{ccf}$, Instead of the $\$ 0.32 / \mathrm{ccf}$ used in the base case, the ratios of payout time and savings from Figs. 16 and 17 are 0.86 and 1.15 , respectively. Thus, the actual local payout time is $15 \times 0.86$, or 13 calendar months, and the local savings would be $\$ 1750 \times 1.15$, or $\$ 2010$ /year. As an alternative to using Figs. 16 and 17 , the factors 0.86 and 1.15 can be calculated as sımple cost ratios, $0.32 / 0.37$ and $0.37 / 0.32$, respectively.

Interest payments were not included in the calculation of payout times, since interest rates vary so widely. If the

Table 5 Major Utilıty Costs

\begin{tabular}{|c|c|c|}
\hline Electric energy, $\mathrm{kWh}$ & Electric demand, kW & Gas \\
\hline $\begin{array}{l}\text { Dehumidıfication } \\
\text { Brıne temperature } \\
\text { Compressor shutdown } \\
\text { at night } \\
\text { Pump shutdown at } \\
\text { night } \\
\text { Ice thickness } \\
\text { Reduced lıghtıng } \\
\text { Power factor } \\
\text { (utilıty option) } \\
\text { Load-cycling controller } \\
\text { Nonradiatıng celling } \\
\text { New lightıng systems }\end{array}$ & $\begin{array}{l}\text { Start-up } \\
\text { Power factor } \\
\text { (consumer option) } \\
\text { Load-shedding } \\
\text { controller }\end{array}$ & $\begin{array}{l}\text { Temperature of } \\
\text { resurfacing water } \\
\text { Snow meltıng } \\
\text { Space heatıng with } \\
\text { condenser heat }\end{array}$ \\
\hline
\end{tabular}

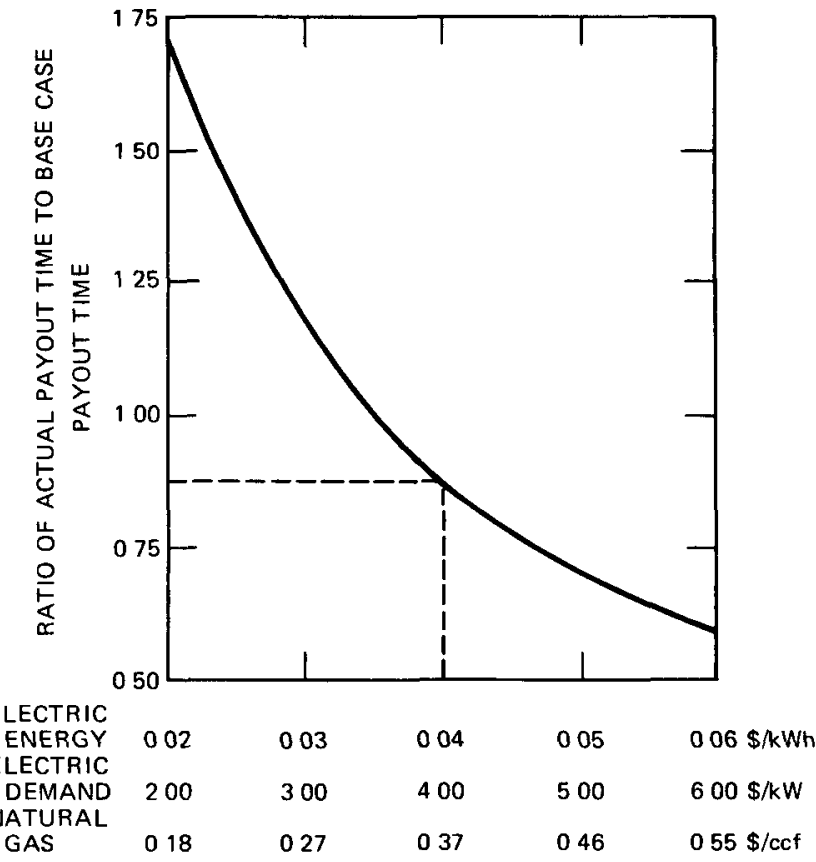

Fig. 16 Change in payout time with various utility rates.

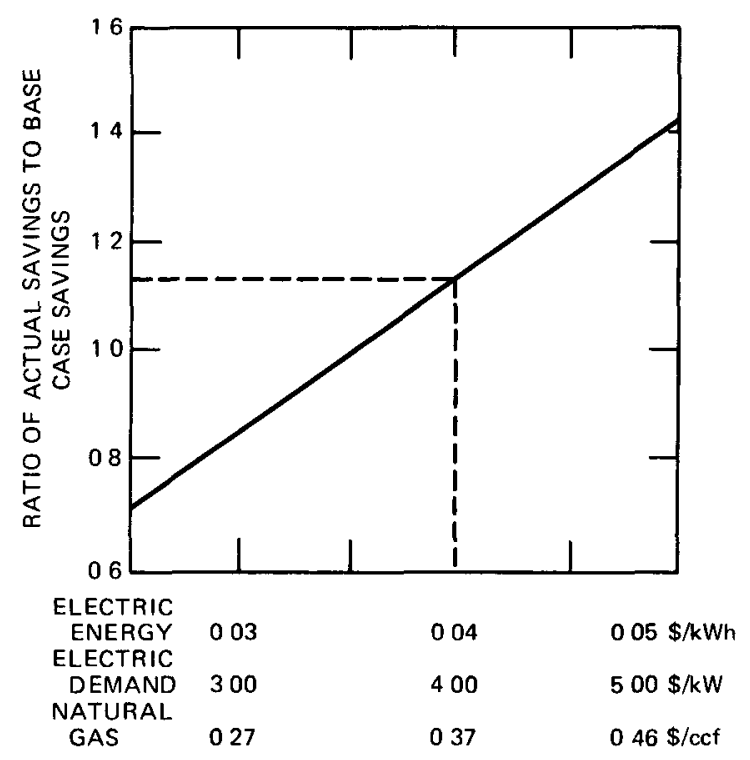

Fig. 17 Change in savıngs with various utility rates. 


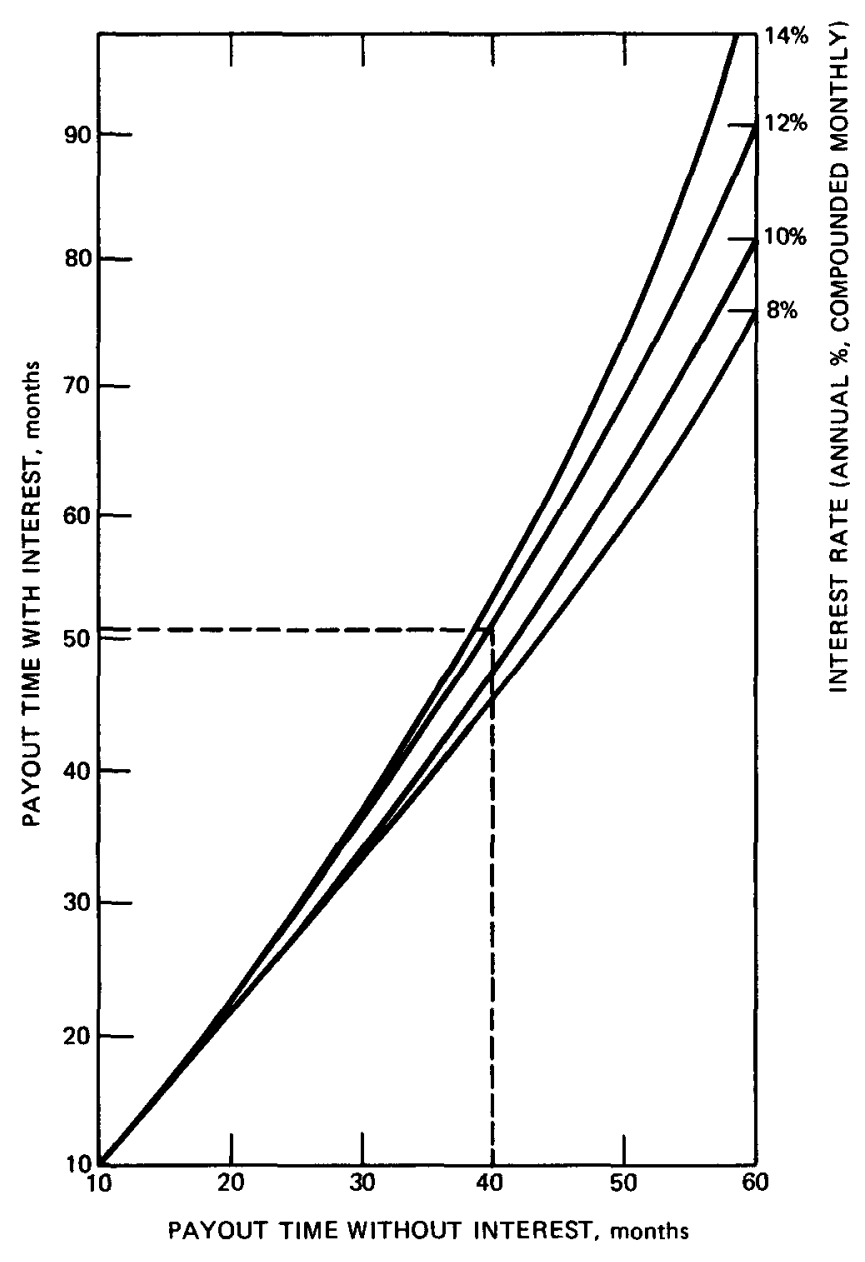

Fig. 18 Payout time with and without interest. payout time is reasonably short (under 24 months), interest will not have much effect on the payout time. For longer payout times, Fig. 18 shows exactly how much longer the payout time will be with the inclusion of interest charges on the money used to make modifications in a rink. For example, suppose a new lighting system has an estimated payout time of 40 months and the money for the new lights is borrowed at $12 \%$ interest. Figure 18 shows that the new payout time, including interest, is $\mathbf{5 1}$ months. 


\section{Appendix 2 Interaction Between Different Modifications}

Many of the modifications suggested in this manual interact with one another, i.e., making one modification may reduce the amount of savings available from some of the other modifications. For example, a more-efficient lighting system produces less heat. Therefore, there is less heat to be removed by the refrigeration system and, consequently, less condenser waste heat that could be used for space heating. Table 6 shows how the savings from each of the modifica- tions affect other modifications that might be made. The purpose of Table 6 is to provide a rough estimate of the effects of interaction. Table 6 looks complicated, but examples are given below to show how it is used.

To use Table 6, run down the column under the modification being considered. Multiply together all of the numbers (or factors) in that column opposite other modifications that are to be made first. The reduced savings

Table 6 Interactions Between Modifications*

\begin{tabular}{|c|c|c|c|c|c|c|c|c|c|c|}
\hline $\begin{array}{l}\text { The payout time } \\
\text { and savings } \\
\text { for these } \\
\text { modifica- } \\
\text { tions } \\
\text { will be } \\
\text { changed } \\
\text { when these } \\
\text { modifications } \\
\text { are first made }\end{array}$ & 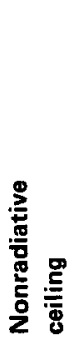 & 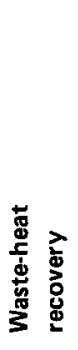 & 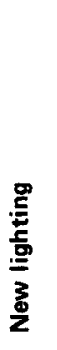 & 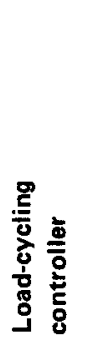 & 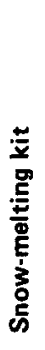 & 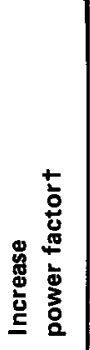 & 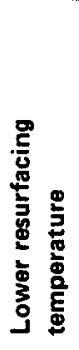 & 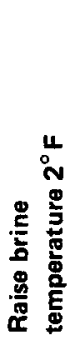 & 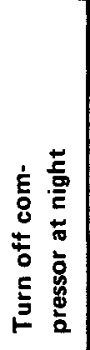 & 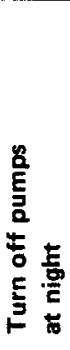 \\
\hline $\begin{array}{l}\text { Nonradiative } \\
\text { ceiling }\end{array}$ & & 0.75 & - & 0.80 & - & 0.80 & - & 0.57 & 0.60 & - \\
\hline $\begin{array}{l}\text { Waste-heat } \\
\text { recovery }\end{array}$ & - & & - & - & - & - & - & - & - & - \\
\hline New lighting & - & 0.96 & & 0.99 & - & - & - & - & - & - \\
\hline $\begin{array}{l}\text { Load-cycling } \\
\text { controller }\end{array}$ & 0.80 & 0.80 & - & & - & 0.80 & - & - & 0 & 0 \\
\hline Snow-melting kit & - & 0.94 & - & - & & - & - & - & - & - \\
\hline $\begin{array}{l}\text { Increase } \\
\text { power factort }\end{array}$ & - & - & - & 0.94 & 一 & & & & - & - \\
\hline $\begin{array}{l}\text { Lower resurfacing } \\
\text { temperature }\end{array}$ & - & 0.97 & - & 0.98 & - & 0.98 & & & - & - \\
\hline $\begin{array}{l}\text { Raise brine } \\
\text { temperature } 2^{\circ} \mathrm{F}\end{array}$ & 0.95 & 0.81 & - & 0.85 & - & 0.85 & - & & 0.60 & - \\
\hline $\begin{array}{l}\text { Turn off com- } \\
\text { pressor at night }\end{array}$ & 0.99 & 0.91 & - & 0.93 & - & 0.93 & - & 0.91 & & \\
\hline $\begin{array}{l}\text { Turn off pumps } \\
\text { at night }\end{array}$ & - & 0.99 & - & 0.99 & - & 0.99 & - & - & 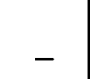 & \\
\hline
\end{tabular}

*Entries shown as - are 1.0.

tIncrease power factor with capacitors (utility option). 
due to interaction are the product of these factors times the original savings. Similarly, the new payout time is the old payout time divided by the product of these factors.

The following example illustrates the calculations that are involved. Consider a rink interested in raising the brine temperature by $2^{\circ} \mathrm{F}$, installing a snow-melting kit, a nonradiative ceiling, and a capacitor to increase their power factor. To find how the other three modifications affect the payout time for the nonradiative ceiling, look at the column of Table 6 labeled "nonradiative ceiling." The only factor for the modifications being considered is 0.95 for "raise brine temperature $2^{\circ} \mathrm{F}$." If the original payout time was estimated at 40 months, the new payout time would be $40 / 0.95$, or 42 months, when the ceiling is installed with the other three modifications. For the altered savings and payout time for the capacitor, the column "increase power factor with capacitors" lists factors of 0.80 and 0.85 opposite "nonradiative ceiling" and "raise brine tempera-. ture," respectively. The product of these two factors $(0.80 \times 0.85)$ is 0.68 . If the original payout time (from Fig. 8) is 30 months and the estimated savings are $\$ 375 /$ year before considering interactions, the new payout time would be $30 / 0.68$, or 44 months, and the savings would be $\$ 375 \times 0.68$, or $\$ 255 /$ year. Table 6 is based on the conservative assumption that it is desired to recover all the waste heat from the condenser. If, for example, it is desired to recover only $75 \%$ of the waste heat, then the entry of 0.75 in Table 6 indicates that the installation of a nonradiative ceiling would have no effect on the payout time for the waste-heat recovery system. An additional, more technical discussion of interaction effects is given at the end of Appendix 4, where the 0 entries for the load-cycling controller are explained. 


\section{Appendix 3 Refrigeration Systems and Heat Balances}

\section{TYPES OF REFRIGERATION SYSTEMS}

To evaluate methods of saving energy in an ice rink requires examining in detail the various types of refrigeration systems that are used in ice rinks. Four types of refrigeration systems are in common use in rinks today: conventional ammonia/brine, conventional Freon/brine, plastic mat (or low flow) Freon/brine, and direct Freon refrigeration.

The first three systems are indirect systems (Fig. 19) in which the primary refrigerant cools a secondary refrigerant, brine, which is then passed under the ice. The term brine as used in the ice rink industry is a misnomer since normally a glycol solution is used for the secondary refrigerant. In the two conventional systems, the brine is passed through $1 / 2$-in. steel pipes under the ice. The difference between the two conventional systems is in the use of ammonia and Freon 22 (monochlorodifluoromethane) for the primary refrigerant.

In the third indirect system the brine is passed under the ice in plastic mat tubing rather than steel pipes. The advantage of the plastic mat system is that the brine flows in both directions within the rink; therefore there can be a much higher temperature rise in the brine between the inlet and outlet and yet still have an even temperature within the ice slab. The higher temperature rise in the brine permits the use of a smaller brine flow rate for the same cooling

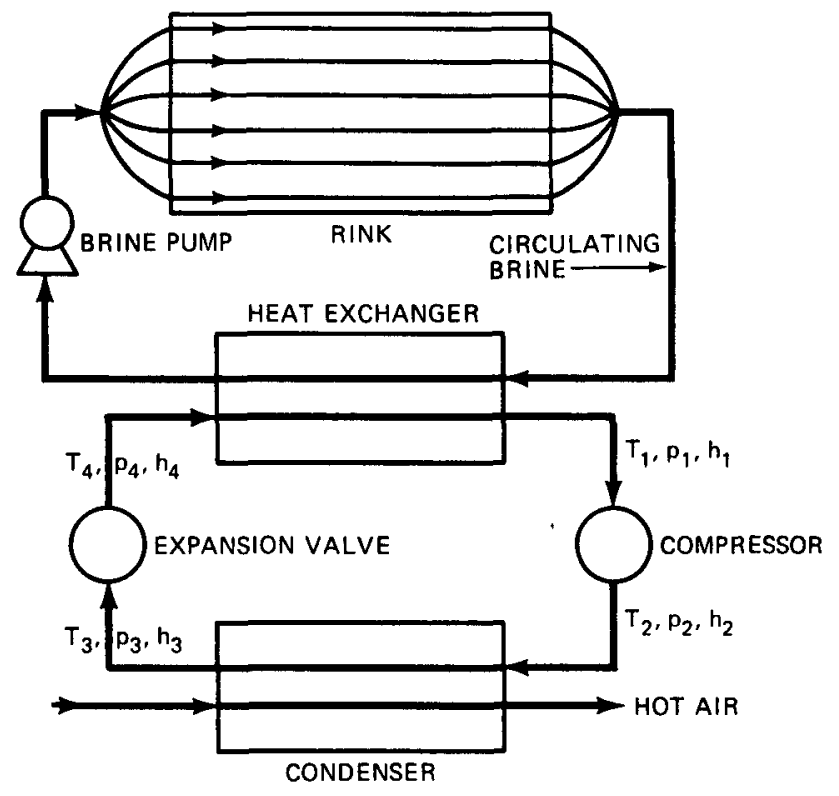

Fig. 19 Diagram of a secondary refrigeration system. capacity. Therefore, much smaller brine pumps (5 hp) are required compared to those required for conventional refrigeration systems, which use 20 - to 30 -hp pumps. ${ }^{1}$ The disadvantage of the plastic mat system, according to competing manufacturers, is that the plastic tubes are easily fouled and the heat transfer coefficient drops drastically over the first three years of operation. ${ }^{2}$ This decrease in heat transfer coefficient results in a continually lower compressor suction temperature and a continually lower efficiency for the plastic mat system. This disadvantage is partially offset by laying the plastic tubes directly on the concrete slab rather than imbedding them in the concrete, as are the steel pipes of the conventional systems. Laying the plastic pipe on top of the concrete slab gives a shorter heat transfer path and hence a lower resistance to heat flow from the ice.

Familiarity with how a refrigeration system works is necessary in order to find the most efficient ways of operating a rink. As shown in Fig. 19, a refrigerant gas (either ammonia or Freon) is compressed adiabatically from temperature $T_{1}$ and pressure $p_{1}$ to a higher temperature and pressure, $T_{2}$ and $p_{2}$. This higher pressure is known as the discharge pressure. The hot refrigerant gas from the compressor is then condensed to a saturated liquid at the same pressure $\left(p_{2}=p_{3}\right)$. The condenser can be either an air-cooled or an evaporative condenser. Air-cooled condensers, although less efficient, are often used in northern ice rinks because evaporative condensers sometimes freeze up in the winter.

Following condensation, the refrigerant liquid passes through an expansion valve which lowers the pressure and temperature of the refrigerant. The expansion is carried out at constant enthalpy so that $h_{3}=h_{4}$. After expansion, the refrigerant passes through a heat exchanger (also called an evaporator or chiller), cooling the secondary refrigerant, or brine, and returns to the compressor. The temperature, $T_{4}$, and the pressure, $p_{4}$ (after expansion), are the same as $T_{1}$ and $p_{1}$, respectively. This temperature and this pressure are referred to as the suction temperature and suction pressure.

The fourth type of refrigeration system, direct Freon refrigeration, eliminates the chiller and brine loop by passing the cold Freon from the expansion valve directly under the ice. The advantages of this system are:

1. No brine pumps are needed since the pressure difference $\left(p_{2}-p_{1}\right)$ moves the refrigerant under the ice.

2. The temperature difference between the brine and the refrigerant in the chiller (usually $10^{\circ} \mathrm{F}$ ) is eliminated. Therefore, for the same ice temperature, the direct refrig- 
eration system will have a $10^{\circ} \mathrm{F}$ higher suction temperature and a resulting higher efficiency.

According to competing manufacturers, the disadvantage of direct refrigeration is that a leak in the piping system under the ice will lead to a complete (and expensive) loss of the Freon charge in the compressor. ${ }^{1}$

\section{COEFFICIENT OF PERFORMANCE}

To calculate a heat balance for an ice rink and to calculate energy savings in refrigeration require knowledge of the efficiency of the refrigeration system. The most common measure of refrigeration efficiency is the coefficient of performance (COP). A compressor COP is defined as the ratio of heat removed by the compressor to the work done to run the compressor, including the compressor motor efficiency. An overall COP can also be defined in which the work term includes the work to run the auxiliary pumps and fans of the entire refrigeration system as well as the work to run the compressor.

The overall COP for a refrigeration system can be calculated from manufacturer's data on the tons of refrigeration and the horsepower of the system:

Overall COP $=\frac{\text { (tons of refrigeration })(12,000 \mathrm{Btu} / \text { ton })}{(\text { horsepower })(2,544 \mathrm{Btu} / \mathrm{hp})}$

A theoretical COP can be calculated from enthalpy values for ammonia and Freon:

$$
\text { Theoretical COP }=\frac{\left(h_{1}-h_{4}\right)}{\left(h_{2}-h_{1}\right)}
$$

The theoretical COP differs from the compressor COP because of the various inefficiencies in the compressor and motor, which are described below. If the theoretical COP is corrected for these inefficiencies and also for the power of the auxiliary motors of the pumps and fans of the entire refrigeration system, a theoretical overall COP is obtained which can be compared to the overall COP calculated from manufacturers' data and Eq. 1. The enthalpy values for use in Eq. 2 can be obtained either from a table of enthalpies and entropies or from a Mollier diagram. A typical Mollier diagram with a refrigeration cycle is shown in Fig. 20 . The subscripts for temperature, pressure, and entropy in Figs. 19 and 20 are the same.

It is most efficient to carry out a refrigeration process at as high a suction temperature as possible, as can be seen in Fig. 20. The lower horizontal line, labeled "evaporation" in Fig. 20, corresponds to the suction temperature. A lower suction temperature will lower the evaporation line. A lower evaporation line, in turn, will decrease the amount of cooling accomplished per cycle $\left(h_{1}-h_{4}\right)$, while the work per cycle $\left(h_{2}-h_{1}\right)$ is increased. Both changes decrease the theoretical COP and hence decrease the efficiency of the refrigeration system. Figure 21 shows this change in theoretical COP for an ammonia compressor as a function of suction temperature for a discharge pressure of 185 psig.

Four factors reduce the theoretical COP obtained from enthalpy data to the actual compressor COP. The first factor is the motor efficiency, which is assumed to be $90 \%$. The other three factors affect the efficiency of the compressor. They are the thermal volume efficiency, $e_{s}$, the effect of clearance in the pistons, and the effect of valve and piston ring leakage and internal friction. The last two factors are of minor importance and are estimated to have an efficiency of $95 \%$ each. The thermal volume efficiency is the greatest of the four factors that reduce refrigeration

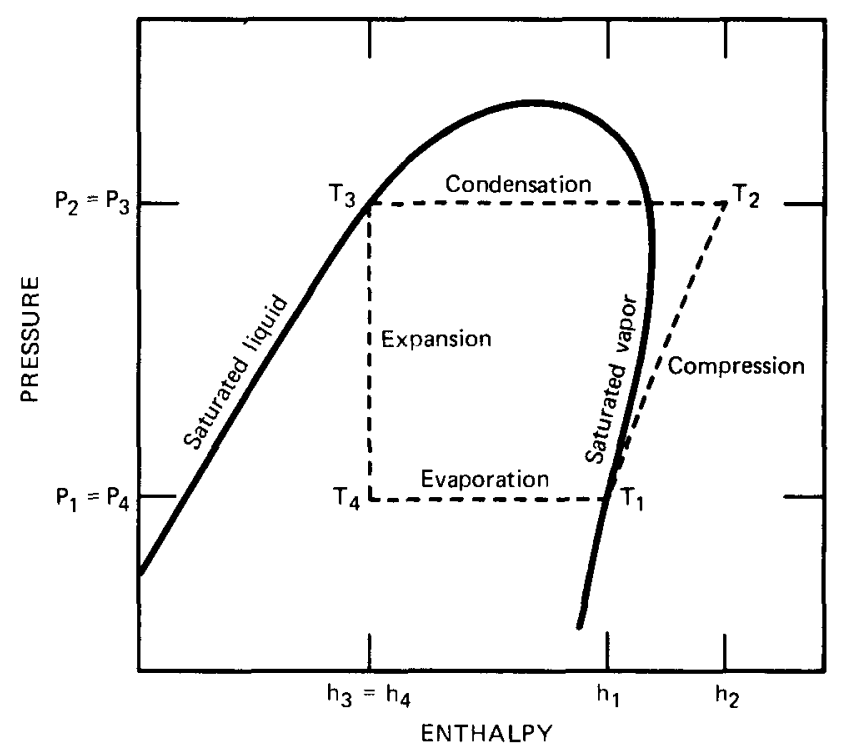

Fig. 20 Mollier diagram with refrigeration cycle.

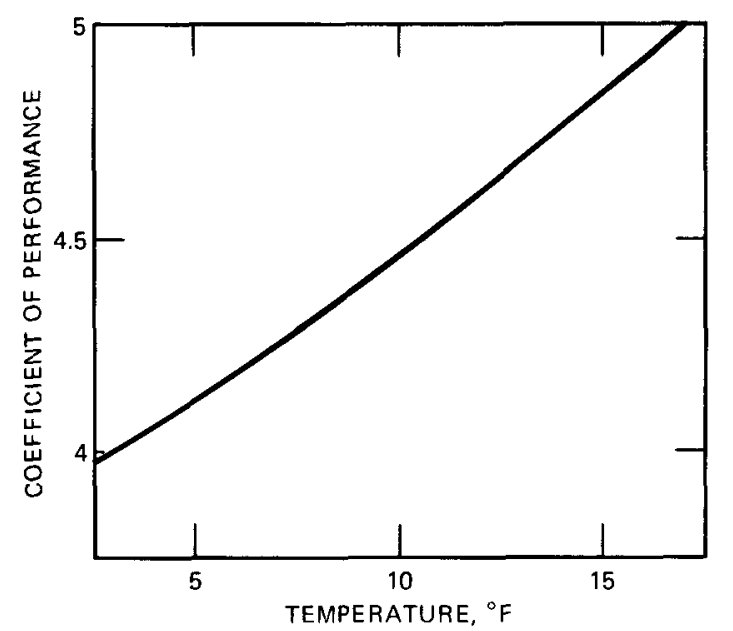

Fig. 21 COP vs. suction temperature for an $\mathrm{NH}_{3}$ compressor with a discharge pressure of 185 psig. 
- efficiency and is due to superheating of the refrigerant gas during the suction stroke of the compressor by contact with the relatively hot cylinder walls. This superheating decreases the density of the refrigerant gas; hence, less refrigerant is pumped per piston stroke, leading to lower efficiencies. The thermal volume efficiency can be estimated from Eq. 3: ${ }^{3}$

$$
e_{s}=1-\frac{\left(T_{2}-T_{1}\right)}{1330}
$$

where $T_{2}$ and $T_{1}$ refer to Fig. 20 and are in ${ }^{\circ} \mathrm{F}$. For typical values of $10^{\circ} \mathrm{F}$ for the suction temperature $\left(T_{1}\right)$ and $220^{\circ} \mathrm{F}$ for the maximum superheat temperature $\left(T_{2}\right), e_{s}=0.84$. Therefore, the three factors that affect compressor performance together have an efficiency of $0.75(0.95 \times$ $0.95 \times 0.84)$.

Table 7 tabulates COP values for the four ice rink systems and compares the theoretical COP values with the actual COP values from manufacturers' data on refrigeration tonnage and horsepower.

The first three columns in Table 7 are based on enthalpy data. The compressor COP column was obtained by correcting the theoretical COP for compressor (0.75) and motor $(0.90)$ efficiencies (COP $\times 0.75 \times 0.9)$. The overall theoretical COP was obtained by multiplying the compressor COP by the ratio of compressor horsepower to total refrigeration horsepower, including all pumps and fans. The agreement between the theoretical overall COP from enthalpy data and the overall COP from measured tons of refrigeration is well within the error in estimating the value of the efficiencies.

The compressor COP column is used to calculate marginal kilowatt-hour savings from a reduced heat load, since the pumps and fans are running continuously regardless of the amount of time that the compressor is running. The marginal electrical energy savings for a reduced heat load are found with Eq. 4:
Savings, kWh

$$
=\frac{(\text { reduction in Btu })\left(2.93 \times 10^{-4} \mathrm{kWh} / \mathrm{Btu}\right)}{(\text { compressor COP })}
$$

To calculate the amount of condenser heat available for space heating, use either Eq. 5 or Eq. 6:

$\mathrm{Btu} / \mathrm{day}=(\mathrm{kWh} /$ day $)(\mathrm{A})(3412 \mathrm{Btu} / \mathrm{kWh})$

$$
x \text { (overall COP) }\left(1+\frac{1}{\text { compressor COP }}\right)
$$

$\mathrm{Btu} /$ day $=(\mathrm{kWh} /$ day $)(B)(3412 \mathrm{Btu} / \mathrm{kWh})$

$$
\times(1+\text { compressor COP })
$$

where $(A)$ is the fraction of power used by the refrigeration system (essentially the total power less the light power) and (B) is the fraction of the total power used by the compressor alone.

\section{HEAT BALANCES}

A heat balance must be worked out for an ice rink to show where significant refrigeration savings can be made and to facilitate calculations of the reduction in refrigeration costs when one or more of the individual heat loads are reduced. Four heat balances were calculated for two rinks, and the results are tabulated in Tables 8 through 11. For Orr Rink in Amherst, heat balances were calculated for day, night, and 24-hr operation at a time of moderate use. A total heat balance was calculated for the North Adams rink during minimal use (light patch and figure skating). At Orr Rink the total heat flow was established from the kilowatthours used by the refrigeration system. At North Adams, the total kilowatt-hour use for the rink was recorded; the electric energy used for the refrigeration system was

\begin{tabular}{|c|c|c|c|c|}
\hline & $\begin{array}{l}\text { Theoretical } \\
\text { COP } \\
\text { enthalpy data }\end{array}$ & $\begin{array}{l}\text { Compressor COP } \\
\text { (theoretical COP } \\
\text { with efficiencies) }\end{array}$ & $\begin{array}{l}\text { Theoretical } \\
\text { overall COP }\end{array}$ & $\begin{array}{c}\text { COP } \\
\text { from manufacturers' } \\
\text { data }^{2,4,5}\end{array}$ \\
\hline $\begin{array}{l}\text { Conventional } \\
\text { ammonia/brine } \\
\text { Conventional }\end{array}$ & 4.85 & 3.27 & 2.74 & $3.55^{*}$ \\
\hline Freon/brine & 4.25 & 2.90 & 2.23 & $2.12,2.05 t$ \\
\hline $\begin{array}{l}\text { Plastic mat } \\
\text { Freon/brine }\end{array}$ & 4.25 & 2.90 & 2.64 & \\
\hline $\begin{array}{l}\text { Direct Freon } \\
\text { refrigeration }\end{array}$ & 5.04 & 3.40 & 3.20 & $3.18,2.95 \dagger$ \\
\hline
\end{tabular}
estimated to be $90 \%$ of the total electric energy used. The convection heat load (the sum of the convective heat

Table 7 Refrigeration Coefficients of Performance 
Table 8 Heat Balance for Orr Rink (16-hr Day Operation)

\begin{tabular}{lcr}
\hline \multirow{2}{*}{ Category } & \multicolumn{2}{c}{ Heat load } \\
\cline { 2 - 3 } & $10^{6}$ Btu & $\%$ \\
\hline Resurfacing & 2.78 & 12 \\
Lighting & 1.65 & 7 \\
Brine pumps & 0.81 & 4 \\
Infrared radiation & 6.46 & 28 \\
Header and ground heat & 2.29 & 10 \\
Skaters & 0.91 & 4 \\
Convection & 8.00 & 35 \\
Total heat load & 22.90 & 100 \\
\hline
\end{tabular}

Table 9 Heat Balance for Orr Rink (8-hr Night Operation)

\begin{tabular}{llr}
\hline & \multicolumn{2}{c}{ Heat load } \\
\cline { 2 - 3 } Category & $10^{6}$ Btu & $\%$ \\
\hline Brine pumps & 0.41 & 6 \\
Infrared radiation & 2.39 & 32 \\
Header and ground heat & 0.75 & 10 \\
Convection & 3.93 & 52 \\
Total heat flow & $\overline{7.48}$ & $\overline{100}$ \\
\hline
\end{tabular}

Table 10 Heat Balance for Orr Rink (24-hr Operation)

\begin{tabular}{lcrc}
\hline \multicolumn{1}{c}{ Category } & \multicolumn{2}{c}{ Heat load } & \multicolumn{1}{c}{$\begin{array}{c}\text { ASHRAE } \\
\text { estimate, }\end{array}$} \\
\cline { 2 - 3 } & $10^{6}$ Btu & $\%$ & 12 \\
\hline Resurfacing & 2.78 & 9 & 8 \\
Lighting & 1.65 & 6 & 15 \\
Brine pumps & 1.22 & 4 & 28 \\
Infrared radiation & 8.85 & 29 & 6 \\
Header and ground heat & 3.04 & 10 & 4 \\
Skaters & 0.91 & 3 & 27 \\
Convection & 11.93 & 39 & $\frac{100}{100}$ \\
Total heat flow & $\overline{30.38}$ & $\underline{100}$ &
\end{tabular}

Table 11 Heat Balance for North Adams (24-hr Operation with Light Use)

\begin{tabular}{|c|c|c|c|}
\hline \multirow[b]{2}{*}{ Category } & \multicolumn{2}{|c|}{ Heat load } & \multirow{2}{*}{$\begin{array}{c}\text { ASHRAE } \\
\text { estimate, } 6\end{array}$} \\
\hline & $10^{6} \mathrm{Btu}$ & $\%$ & \\
\hline Resurfacing & 0.70 & 4.5 & 12 \\
\hline Lighting & 0.60 & 4 & 8 \\
\hline Brine pumps & 1.54 & 10 & 15 \\
\hline Infrared radiation & 4.75 & 31 & 28 \\
\hline Header and ground heat & 1.37 & 9 & 6 \\
\hline Skaters & 0.10 & 0.5 & 4 \\
\hline Convection & 6.35 & 41 & 27 \\
\hline Total heat flow & 15.41 & 100 & $\overline{100}$ \\
\hline
\end{tabular}

transfer and the latent heat effect of convective mass transfer) was found by subtracting the other heat sources from the total heat flow. The heat and mass transfer coefficients implied by this value of the convective heat load are calculated in Appendix 5 and compared to independently estimated heat and mass transfer coefficients.

There is some variation in the heat loads between day and night operation, between heavy and light use, and between the estimates presented here and the ASHRAE estimates. ${ }^{7}$ The greatest variation between the present and the ASHRAE estimates of the heat loads is in the convection heat term. The present estimate (36\% to $44 \%$ ) was obtained by subtracting all the other heat loads from the total heat load determined from the kilowatt-hours used by the refrigeration system. The ASHRAE estimate (27\%) of the convective heat load is based on direct measurements (unpublished) of the temperature gradients above the ice surface and within the ice slab. In Appendix 5 the present estimate of the convective heat load is shown to give reasonable values for the heat and mass transfer coefficients.

The ASHRAE value for the brine pump heat load seems high since the pump heat load can be estimated by

$\%$ pump heat load

$$
=\frac{(\text { pump hp) } \times 100}{\text { (average compressor hp)(compressor COP })}
$$

This equation assumes that all the electrical energy used by the pump is converted into heat.

For a rink with 20-hp pumps and a conventional Freon/brine refrigeration system that averages $100 \mathrm{hp}$, the pump heat load would be $7 \%$ rather than $15 \%$, as estimated by ASHRAE.

In spite of the variations in the heat balances, the relative heat loads should be accurate enough to predict the reduction in total refrigeration costs from reducing one or more of the individual heat loads.

\section{REFERENCES}

1. Personal communication, Vincent Godleski, Marketing Manager, ITT Ice Rinks, Midland Park, N.J.

2. Ice Rink Buying and Specifying Guide, Holmsten Ice Rinks Inc., St. Paul, Minn.

3. H. J. Maclntire and F.W. Hutchinson, Refrigeration Engineering, John Wiley \& Sons, N.Y., 1950.

4. Cold Flo /ce Rink Systems, Frick Corp., St. Louis, Mo.

5. Personal communication, Richard Holmsten, Pres., Holmsten Ice Rinks Inc., St. Paul, Minn.

6. A. Bennett, Ed., ASHRAE Handbook, American Society of Heating, Refrigeration, and Air Conditioning Engineers, New York, 1978.

7. Personal communication, John Connelly, Rink Design Consultants, Syracuse, N.Y. 


\section{Appendix 4 Calculations of Energy and Dollar Savings}

This manual has been written so that it can be used by those who have a minimal engineering background. Thus many of the calculations and data were omitted from the text. The calculations, data, and assumptions not included in the text are detailed in this Appendix. The order of topics in the Appendix parallels those in the text.

\section{DESCRIPTION OF EXPERIMENTAL EQUIPMENT}

Most of the data in the manual were obtained from rink managers, rink consultants, and manufacturers of ice rink equipment. Some experimental work, however, was carried out at Orr Rink in Amherst, the state rink at North Adams, and the Williston Academy Rink in Easthampton. The temperatures of the rink ceiling, ice surface, and ice slab interior were measured with thermistors and an ohm meter. The air temperature and humidity were measured with a 7-day recording hygro-thermograph. The calibration of both the thermistors and the hygro-thermograph was checked with an ice bath. Electric power and energy were recorded with a watt-varmeter and transducer and chart recorder. The chart recorder was used at $3 \mathrm{in} . / \mathrm{hr}$.

\section{RESURFACING WATER TEMPERATURE}

The heating and subsequent refrigeration of the water used for resurfacing is a small but important area for energy conservation. Calculations were done to find the amount of money that can be saved by reducing the temperature of the resurfacing water. The following assumptions, based on a survey by the Zamboni Co., ${ }^{1}$ were used for the energy calculations:

- Ice is resurfaced 8 times per day.

- $180 \mathrm{gal}$ of water is heated from $60^{\circ} \mathrm{F}$ to $180^{\circ} \mathrm{F}$ to fill the Zamboni.

- 140 of the $180 \mathrm{gal}$ of hot water is actually used for resurfacing.

- The final surface temperature of the ice is $24^{\circ} \mathrm{F}$.

- Evaporative cooling and heat transfer to the ice each account for $50 \%$ of the heat load in cooling the hot resurfacing water to $32^{\circ} \mathrm{F}$.

The fraction of the resurfacing water that evaporates can be calculated by equating half of the sensible heat to the latent heat of vaporization times the fraction of water that evaporates. This procedure gives a value of 0.071 for the fraction of water that evaporates. With these assumptions, the heat load per resurfacing is

$$
\begin{aligned}
\mathrm{Q}= & (140 \mathrm{gal})(8.3 \mathrm{lb} / \mathrm{gal})\{\underbrace{}_{\text {sensible heat of water }}(\underbrace{180^{\circ} \mathrm{F}-32^{\circ} \mathrm{F}}_{\text {latent heat of fusion }}) \\
& +(1-0.071)[\underbrace{44 \mathrm{Btu} / \mathrm{lb}}_{\text {sensible heat of ice }} \\
& \left.\left.+(\underbrace{\left.32^{\circ} \mathrm{F}-24^{\circ} \mathrm{F}\right)\left(0.49 \mathrm{Btu} / \mathrm{lb} \cdot{ }^{\circ} \mathrm{F}\right.})\right]\right\} \\
= & 2.44 \times 10^{5} \mathrm{Btu} / \text { resurfacing } \\
= & 1.9 \times 10^{6} \mathrm{Btu} / \text { day }
\end{aligned}
$$

The monthly dollar savings in refrigeration costs for reducing the temperature of resurfacing water from $T^{\circ} \mathrm{F}$ to $130^{\circ} \mathrm{F}$ can be calculated from

$$
\begin{aligned}
\text { Electrical savings }= & \left(T^{\circ} \mathrm{F}-130^{\circ} \mathrm{F}\right)(140 \mathrm{gal}) \\
& \times(8.3 \mathrm{lb} / \mathrm{gal})(240 \text { resurf./month }) \\
& \times\left[\left(2.93 \times 10^{-4} \mathrm{kWh} / \mathrm{Btu}\right)\right. \\
& \times(\$ 0.035 / \mathrm{kWh})] \\
& \times(2 \times \mathrm{COP})^{-1}
\end{aligned}
$$

The factor 2, which multiplies the COP, results from the assumption that evaporative cooling contributes $50 \%$ to cooling the hot resurfacing water. The monthly gas savings for $130^{\circ} \mathrm{F}$ resurfacing water can be calculated from

$$
\begin{aligned}
\text { Gas savings }= & \left(\mathrm{T}^{\circ} \mathrm{F}-130^{\circ} \mathrm{F}\right)(180 \mathrm{gal}) \\
& \times(8.3 \mathrm{lb} / \mathrm{gal})(240 \text { resurf./month }) \\
& \times \frac{\$ 0.32 / \mathrm{ccf}}{10^{5} \mathrm{Btu} / \mathrm{ccf}} \times(0.7)^{-1}
\end{aligned}
$$

The 0.7 factor is the efficiency assumed for the gas heater. Equations 7 and 8 with a COP of 2.9 for a conventional Freon/brine refrigeration system were used to construct Fig. 2.

\section{INCREASE IN REFRIGERANT TEMPERATURE}

An increase in refrigerant temperature reduces refrigeration costs in two ways. First, a higher refrigerant temperature causes an increase in the ice surface temperature, which results in lower convective and conductive heat transfer, lower radiant heat transfer, and lower convective mass transfer loads. Second, a higher refrigerant tempera- 
ture results in a higher COP for the compressor and greater efficiency in the refrigeration system.

The decrease in refrigeration costs is calculated for an increase in compressor suction temperature from $10^{\circ} \mathrm{F}$ to $12^{\circ} \mathrm{F}$ and a consequent rise in ice surface temperature from $22^{\circ} \mathrm{F}$ to $24^{\circ} \mathrm{F}$. The calculated decrease in refrigeration costs is then compared to measured decreases in kilowatt-hour use at two rinks for a $2^{\circ} \mathrm{F}$ rise in refrigerant temperature.

If it is assumed that the air temperature next to the ice is $37^{\circ} \mathrm{F}$ and the ceiling temperature is $60^{\circ} \mathrm{F}$, an increase in the ice surface temperature from $22^{\circ} \mathrm{F}$ to $24^{\circ} \mathrm{F}$ would result in a $13 \%$ smaller $\Delta \mathrm{T}$ for convective heat transfer, an $11 \%$ smaller $\Delta \mathrm{x}$ for mass transfer, and a $5 \%$ lower $\Delta \mathrm{T}^{4}$ for radiant heat transfer. Using the heat balance of Table 10 for the relative importance of each heat load, you find that a $2^{\circ} \mathrm{F}$ higher refrigerant temperature results in a $7 \%$ lower heat load.

The increase in compressor efficiency for an increase in suction temperature from $10^{\circ} \mathrm{F}$ to $12^{\circ} \mathrm{F}$ is calculated from Fig. 21, which is based on enthalpy tables for ammonia. The COP is increased from 4.85 to 5.03 , or $4 \%$. Therefore, the predicted decrease in refrigeration costs for a $2^{\circ} \mathrm{F}$ rise in refrigerant temperature is $11 \%$. The measured decreases in energy costs were $14 \%$ at North Adams and $15 \%$ at Ridgefield for a $2^{\circ} \mathrm{F}$ change in temperature. The difference in measured and predicted decreases in refrigeration costs is probably due to the error $\left( \pm 0.5^{\circ} \mathrm{F}\right)$ in measuring the brine temperature.

\section{TURNING OFF THE HEAT AT NIGHT}

The refrigeration savings that can be achieved by turning off the heat at night results from four factors. First, the lower ceiling temperature reduces radiation to the ice. Second, the lower air temperature reduces the $\Delta T$ for convective heat transfer. Third, the heating system fans increase the air speed, which in turn increases both heat and mass transfer coefficients. Fourth, the fans increase the temperature and humidity of the air near the ice surface by mixing the otherwise stagnant air layers.

For purposes of calculations, it was estimated that, to maintain a $50^{\circ} \mathrm{F}$ temperature throughout the rink at night (as is done at Orr Rink), the heating system would be on for $20 \%$ of the night. It was further assumed that the heating system fans create air currents of $1 \mathrm{mph}$ while the heating system is on. At the North Adams rink, the temperature dropped to between $38^{\circ} \mathrm{F}$ and $40^{\circ} \mathrm{F}$ at night in late winter with the heating system off; it was assumed that the same temperature drop would occur at Orr Rink in the absence of heating.

For an ice surface at $18^{\circ} \mathrm{F}$, the radiant heat load from a $50^{\circ} \mathrm{F}$ ceiling is $58 \%$ greater than the load from a $39^{\circ} \mathrm{F}$ ceiling. Changes in the radiant heat load are approximately linear over a $20^{\circ} \mathrm{F}$ range. With the additional assumption that the decrease in ceiling temperature is linear in time, the average increase in the radiant heat load would be $28 \%$ as a " result of heating the rink at night. The convective heat transfer coefficient for the ice surface can be estimated using Eq. 9, which applies for inside flat walls: ${ }^{2}$

$$
h=0.6+0.28 V
$$

where $h$ is in Btu/ $\mathrm{ft}^{2} \cdot h r$ and $V$ is the air velocity in mph. Therefore, $h$ increases by $50 \%$ for an increase in air velocity from 0 to $1 \mathrm{mph}$. With the use of the Chilton Colburn analogy, ${ }^{3}$ the mass transfer coefficient is found to be increased by $50 \%$ also.

The temperature immediately ( 8 in.) above the ice surface at North Adams fell to $32^{\circ} \mathrm{F}$ in the absence of heating at night compared to $37^{\circ} \mathrm{F}$ at Orr Rink with heating. Therefore, heating the rink at night increases the temperature gradient for convective heat transfer by as much as $35 \%$. It was estimated that for the entire night the average temperature gradient would be increased by $20 \%$ by heating the rink at night. The greater temperature gradient and larger heat transfer coefficient combine to give an estimated increase of $32 \%$ in the convective heat load as a result of maintaining a $50^{\circ} \mathrm{F}$ temperature at night.

From the above increases in heat loads and the night heat balance for Orr Rink (Table 9), the increase in refrigeration load when the night temperature is maintained at $50^{\circ} \mathrm{F}$ is found to be $26 \%$. No attempt was made to estimate the increase in refrigeration load caused by the mixing of stagnant air layers within the rink when the heating fans are on. However, an ASHRAE report ${ }^{4}$ states that this destruction of the air stratification causes a major increase in the heat load.

\section{TURNING COMPRESSORS OFF AT NIGHT}

Two experts on rink operation have recommended turning rink compressors off at night as a method of saving energy and money. The physical basis for the savings in energy is a reduction in the total nightly heat flow into the ice slab. This reduction in total heat flow results from the rise in the temperature of the ice surface when the compressor is turned off for the night. The rise in surface temperature results in a lower $\Delta T$ for convective heat transfer, a lower $\Delta \mathrm{x}$ for convective mass transfer, and a lower $\Delta \mathrm{T}^{4}$ for radiant heat transfer. These effects can be estimated and compared to the measured energy consumption for the rink with and without the compressor running at night.

During the late winter, temperature and relative humidity were $37^{\circ} \mathrm{F}$ and $80 \%$, respectively, for most of the night at Orr Rink at a point about 8 in. above the ice surface. At a point $20 \mathrm{ft}$ off the ice, the air temperature and relative humidity were $50^{\circ} \mathrm{F}$ to $55^{\circ} \mathrm{F}$ and $40 \%$, respectively. The average ceiling temperature at the midpoint of the rink was $45^{\circ} \mathrm{F}$ at night. The surface temperature of the ice was 
measured with a thermistor wedged into a crack in the ice surface and covered with a thin layer of packed snow.

The compressor at Orr Rink was turned off at 10:30 p.m., $30 \mathrm{~min}$ before the ice was clear of skaters. Figure 22 shows the rise in the surface temperature (after $11: 30$ p.m.) with the compressor off and the subsequent recovery period when the compressor was restarted (4 a.m.). The initial drop in surface temperature (11 to 11:30 p.m.) was due to a decrease in the heat load at night with no skaters, no lights, and reduced heat and mass transfer coefficients. With the reduced heat load, the heat sink provided by the reservoir of cold brine dropped the temperature of the ice surface to $18^{\circ} \mathrm{F}$. This same drop in the surface temperature was recorded at night whether the compressors were on or off. The integrated average temperature from Fig. 22 was $23.1^{\circ} \mathrm{F}$ for the 8 -hr period (11 p.m. to 7 a.m.) compared to $18^{\circ} \mathrm{F}$ when the compressors run all night.

Table 12 lists the decreases in driving forces for heat and mass transfer which result from shutting off the compressor. These percent changes in the driving forces and the night heat balance from Table 9 were used to calculate the expected decrease in heat flow to the ice as a result of turning the compressor off at night:

$$
\% \text { change in heat load }=\underbrace{32 \times(0.17)}_{\begin{array}{c}
\text { radiant } \\
\text { heat load }
\end{array}}+\underbrace{52 \times(0.25)}_{\begin{array}{c}
\text { convective } \\
\text { heat load }
\end{array}}=18 \%
$$

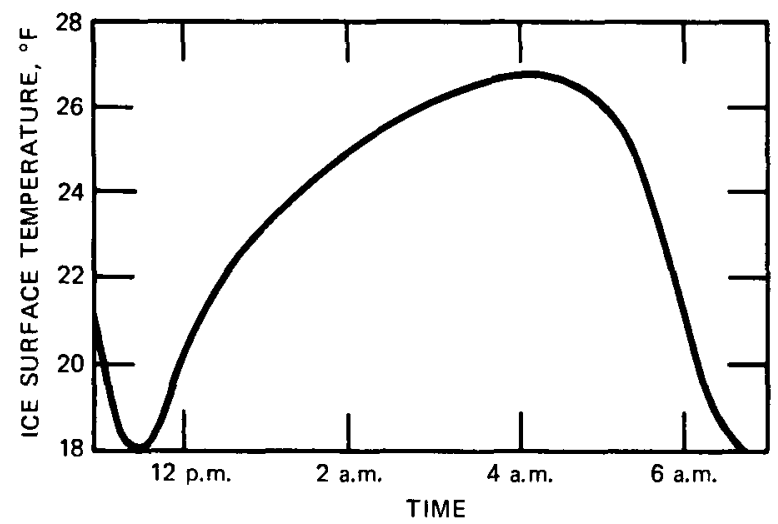

Fig. 22 Rise in ice surface temperature with the compressor turned off.

Table 12 Reduced Driving Forces for Heat and Mass Transfer*

\begin{tabular}{lccc}
\hline & $\Delta \mathrm{T}^{\circ}{ }^{\circ} \mathrm{F}$ & $\Delta \times \times 10^{-3}$ & $\Delta \mathrm{T}^{4} \times 10^{-4},\left({ }^{\circ} \mathrm{F}\right)^{4}$ \\
\hline $18^{\circ} \mathrm{F}$ surface & 19 & 2.5 & 128 \\
$23^{\circ} \mathrm{F}$ surface & 14 & 1.9 & 106 \\
$\%$ decrease & 26 & 24 & 17 \\
\hline
\end{tabular}

* $x$ = mole fraction $\mathrm{H}_{2} \mathrm{O}$ in air.
Table 13 lists the kilowatt-hour use for the period 11 p.m. to 7 a.m. for the third week of February 1979. On the three nights that the compressor was shut off, it was restarted in time for the ice temperature profile to have returned to normal by the end of the kilowatt-hour measurement period, i.e., 7 a.m.

The measured decrease in electric energy consumption for the night when the compressor was turned off for $6 \mathrm{hr}$ $(34 \%)$ was much greater than the calculated decrease $(18 \%)$. One possible explanation for this discrepancy is that a compressor runs most efficiently when fully loaded. When the compressor is on all night at Orr Rink, it runs partially loaded (usually at $50 \%$ of full power). However, if the compressor is shut down for $6 \mathrm{hr}$ at night, it will run fully loaded for the $2 \mathrm{hr}$ that it takes to return the ice temperature to normal following the shutdown. Therefore, there would be an increase in compressor efficiency in addition to the decreased heat load when the compressor is shut off at night. Another possible explanation for the discrepancy is that the actual driving forces for heat and mass transfer differ from those given in Table 12.

Most new rinks have compressors that only operate fully loaded. Therefore, the savings at these rinks may not be as high as the savings measured at Orr Rink. Nevertheless, the $18 \%$ reduction in night refrigeration costs predicted for a reduced heat load alone would result in a significant reduction $(4 \%)$ in the total refrigeration bill.

\section{ICE THICKNESS}

For a given heat load, the cost of refrigeration can be minimized by running the compressor at as high a suction temperature as possible, with in the limits set for ice quality. A maximum temperature for the ice surface is fixed by the use of the rink. Therefore, the only way to increase the suction temperature is to decrease the temperature difference between the refrigerant and the ice surface.

Since the brine pipes are laid in a cement base (occasionally in sand for older rinks), there are several heat resistances involved in heat transmission from the ice surface to the brine. These resistances are conduction within the ice, cement, and pipe walls and a heat transfer

Table 13 Electrical Energy Consumption at Night at Orr Rink

\begin{tabular}{ccc}
\hline $\begin{array}{c}\text { Compressor } \\
\text { off, hr }\end{array}$ & $\begin{array}{c}\text { 8-hr } \\
\text { consumption, } \\
\text { kWh }\end{array}$ & $\begin{array}{c}\text { Decrease from } \\
\text { average with } \\
\text { compressors on, \% }\end{array}$ \\
\hline 0 & 879 & \\
3 & 749 & 14 \\
3.5 & 722 & 17 \\
0 & 906 & \\
0 & 886 & \\
0 & 825 & 34 \\
6 & 574 & \\
0 & 850 & \\
\hline
\end{tabular}


resistance between the brine and the inside wall of the pipes. The only resistance that can be controlled is the thickness of the ice slab, and the question that must be addressed is the importance of conduction within the ice slab compared to the other heat resistances.

A temperature profile at the North Adams rink was measured by thermistors at the ice surface, ice base, and 0.5 in. above the base. The ice thickness was $1.5 \pm 0.25$ in., and the brine temperature was measured by mercury thermometers. Table 14 shows the temperature profile for

Table 14 Temperature Profile

$\left({ }^{\circ} F\right)$ Within the Ice Slab

\begin{tabular}{cccc}
\hline Brine & Base & 0.5 in. & $\begin{array}{c}\text { Surface } \\
(1.5 \text { in. })\end{array}$ \\
\hline 22.0 & 22.0 & 22.5 & 26.2 \\
24.0 & 24.2 & 24.7 & 28.1 \\
\hline
\end{tabular}

two different brine temperatures. All temperature measurements were accurate to within $0.5^{\circ} \mathrm{F}$. Since there was no significant temperature difference between the ice base and the brine, the major heat resistance must be conductivity within the ice itself. This result is unexpected, and we are at a loss to explain it. The pipe wall and the pipe brine interface should offer negligible heat transfer resistance. However, the refrigerant pipes are covered by 0.5 in. of concrete, ${ }^{5,6}$ which has a conductivity of between 2.5 and $15 \mathrm{Btu} \cdot \mathrm{in.} / \mathrm{ft}^{2} \cdot \mathrm{hr} \cdot{ }^{\circ} \mathrm{F}$ (Refs. 2, 7, and 8). Therefore, it would be expected that the concrete would have a temperature difference of between $33 \%$ and $200 \%$ that of the ice.

A second criterion to judge the relative importance of various heat resistances is provided by the difference between the surface and brine temperatures. Equation 10 relates the steady-state heat flux to the temperature difference between the surfaces of a composite sheet made of even layers of materials with dissimilar thermal properties. $^{3,8}$ In Equation 10, $\mathrm{h}$ is the heat transfer coefficient from the pipe wall to the refrigerant, and $y_{j}$ and $k_{j}$ are the thickness and thermal conductivities, respectively, of material j.

$$
\Delta T=Q\left(\frac{1}{h}+\sum \frac{y_{j}}{k_{j}}\right)
$$

At North Adams, the heat load, $\mathrm{Q}$, was measured by the watt-hour meter for the rink. It was estimated that $90 \%$ of the total rink power was used for the refrigeration system and that the overall COP for the refrigeration system was 2.23. This procedure gave a value of $15.4 \times 10^{6} \mathrm{Btu} / \mathrm{day}$ for the heat load at North Adams, or $38 \mathrm{Btu} / \mathrm{ft}^{2} \cdot \mathrm{hr}$. If it is assumed that conduction within the ice is the only significant term within the parentheses of Eq. 10, then the temperature difference between the brine and the ice surface can be calculated as $3.8 \pm 0.6^{\circ} \mathrm{F}$ using $\dot{k}_{\text {ice }}=15$ Btu $\cdot$ in. $/ \mathrm{ft}^{2} \cdot \mathrm{hr} \cdot{ }^{\circ} \mathrm{F}$ (Refs. 2 and 7 ). This value for $\Delta \mathrm{T}$ is well within the measured value of $4.1 \pm 0.5^{\circ} \mathrm{F}$. Therefore, the conclusions from the above measurements are that the ice slab is the major heat resistance between the ice surface and the brine and that permitting the ice slab to gradually increase in thickness can add significantly to the cost of refrigeration. Again, however, we should note the anomalous nature of the measured temperature profile.

The relative penalty in increased refrigeration costs for using thicker ice than necessary can be calculated from Eq. 10 and Fig. 21 for COP vs. suction temperature. Table 15 lists the suction temperatures and COP values corresponding to ice of various thicknesses with a surface temperature held at $25^{\circ} \mathrm{F}$. A $10^{\circ} \mathrm{F}$ difference between the brine and refrigerant temperatures was assumed. Two different heat loads were used: $75 \mathrm{Btu} / \mathrm{ft}^{2} \cdot \mathrm{hr}$ for winter operation and $130 \mathrm{Btu} / \mathrm{ft}^{2} \cdot \mathrm{hr}$ for summer operation. The value of $75 \mathrm{Btu} / \mathrm{ft}^{2} \cdot \mathrm{hr}$ was obtained by dividing the heat load for Orr Rink given in Table 10 by the surface area of the ice $\left(17,000 \mathrm{ft}^{2}\right)$. The data in Table 15 were used to plot Fig. 5.

\section{SNOW MELTING}

Most rinks melt the snow scraped up during resurfacing with hot water. This procedure requires a large volume of gas as well as increased water and sewer charges. Two alternative procedures are (1) to pipe hot refrigerant from the compressor through the snow-melting pit and (2) to install a small heat exchanger in front of the rink condenser and pipe the hot water from the heat exchanger through the snow pit. The latter arrangement is illustrated in Fig. 6.

The amount of money that is saved by using heat from the refrigeration system to melt the snow can be calculated from the following assumptions:

- Snow (at $32^{\circ} \mathrm{F}$ ) equivalent to $140 \mathrm{gal}$ of water is removed per resurfacing.

- The rink is resurfaced 240 times per month.

- A $70 \%$ efficient gas water heater is used to heat the water for resurfacing.

- The water heater inlet temperature is $60^{\circ} \mathrm{F}$ and the outlet temperature is $160^{\circ} \mathrm{F}$.

- The temperature of the water drained from the snow pit is $50^{\circ} \mathrm{F}$.

Table 15 COP vs. Ice Thickness

\begin{tabular}{|c|c|c|c|c|c|c|}
\hline \multirow{2}{*}{$\begin{array}{c}\text { Ice } \\
\text { thickness, } \\
\text { in. }\end{array}$} & \multicolumn{3}{|c|}{ Winter } & \multicolumn{3}{|c|}{ Summer } \\
\hline & $\Delta T,{ }^{\circ} F$ & $\boldsymbol{T}_{\text {suction. }}{ }^{\mathrm{F}}$ & COP & $\Delta T,{ }^{\circ} F$ & $\mathbf{T}_{\text {suction, }}$ & COP \\
\hline 0.75 & 3.8 & 11.2 & 4.55 & 6.6 & 8.4 & 4.36 \\
\hline 1.0 & 5.0 & 10.0 & 4.47 & 8.7 & 6.3 & 4.22 \\
\hline 1.5 & 7.5 & 7.5 & 4.29 & 13.0 & 2.0 & 3.94 \\
\hline 2.0 & 10.0 & 5.0 & 4.13 & 17.3 & -2.3 & 3.69 \\
\hline
\end{tabular}


"The mass of snow melted per month is

(140 gal/resurf.)(8.3 lb/gal)(240 resurf./month)

$$
=2.79 \times 10^{5} \mathrm{lb} / \text { month }
$$

The heat required to melt the snow is

$\left(2.79 \times 10^{5} \mathrm{lb} /\right.$ month $)[144 \mathrm{Btu} / \mathrm{lb}$

$$
\left.+\left(50^{\circ} \mathrm{F}-32^{\circ} \mathrm{F}\right) \mathrm{Btu} / \mathrm{lb}\right]=4.52 \times 10^{7} \mathrm{Btu} / \mathrm{month}
$$

The hot water necessary to provide this heat is

$\left(4.52 \times 10^{7} \mathrm{Btu} /\right.$ month $)(0.12 \mathrm{gal} / \mathrm{lb}) /\left(160^{\circ} \mathrm{F}-50^{\circ} \mathrm{F}\right)$

$$
=4.95 \times 10^{4} \mathrm{gal} / \mathrm{month}
$$

At a cost of $\$ 0.35 /$ ccf for water and $\$ 0.20 /$ ccf for sewer charges, ${ }^{9}$ the water and sewer costs for the extra water necessary to melt the snow is

$$
\left(4.95 \times 10^{4} \mathrm{gal} / \text { month }\right)\left(1.34 \times 10^{-3} \mathrm{gal} / \mathrm{ccf}\right)(\$ 0.55 / \mathrm{ccf})
$$$$
=\$ 36 / \text { month }
$$

The cost of the gas needed to heat the hot water is based on a gas price of $\$ 0.32 / \mathrm{ccf}$, a heat content of $10^{5} \mathrm{Btu} / \mathrm{ccf}$, and a $70 \%$ efficiency for the water heater. ${ }^{10}$ The gas costs are

$\left(4.95 \times 10^{4} \mathrm{gal} / \mathrm{month}\right)(8.3 \mathrm{lb} / \mathrm{gal})\left(160^{\circ} \mathrm{F}-60^{\circ} \mathrm{F}\right)$

$$
\times\left[(\$ 0.32 / \mathrm{ccf})\left(0.7 \times 10^{5} \mathrm{Btu} / \mathrm{ccf}\right)^{-1}\right]=\$ 188 / \text { month }
$$

The total savings for using waste heat for snow melting would be $\$ 224$ per month. This value was used to construct Fig. 7.

\section{POWER FACTOR IMPROVEMENT}

The induction motors used to run the compressors, pumps, and fans in an ice rink have a current phase lag caused by the induction of the motor windings. The result of this current lag is that induction motors draw more power than they actually use. The excess (or reactive power) is returned to the line but is not recorded on a watt-hour/demand meter. Electric power companies, however, must have a larger generating capacity to provide this reactive power. To pay for the extra generating capacity, electric utilities increase the measured kilowatt demand by an amount proportional to the reactive power to arrive at the billing demand.

The ratio of the actual power used by the rink to the actual power plus the reactive power is called the power factor. The power factor is equal to the cosine of the current phase lag. Since the current phase lag is caused by inductance in the electrical system, the phase lag can be decreased by adding capacitance to the system. This can be accomplished by installing an industrial-sized capacitor at the main rink switchboard. An appropriately sized capacitor can increase the power factor for an ice rink ${ }^{11}$ from between 0.7 and 0.8 to 0.95 .

The advantage to the rink owner in increasing the power factor is a reduction in electric heat losses $\left(1^{2} R\right)$ owing to the reduction in reactive current in the motor windings. This reduction amounts to $0.6 \%$ of the kilowatthours used by the rink motors (about $0.5 \%$ of the total kilowatt-hours) for each 0.10 increase in the power factor. ${ }^{12}$ Since power factors can be increased by 0.15 to 0.25 , the possible electric energy savings are $0.75 \%$ to $1.25 \%$ of the total rink electric energy bill.

Some rinks have utility schedules that provide for a reduction in kilowatt demand billing if the power factor is increased. However, the schedule for most rinks does not provide for this reduction, and the dollar savings for these rinks must come from the reduced $\mathrm{I}^{2} \mathrm{R}$ losses alone. The payout time for a capacitor based on $I^{2} R$ losses only is 14 months, independent of the size of the capacitor. ${ }^{13}$ Typical installation costs are $50 \%$ of the cost of the capacitor. ${ }^{11}$ Therefore, payout time based on the installed cost of an industrial capacitor is $\mathbf{2 1}$ months for year-round operation. Those few rinks which receive a reduction in demand for increasing their power factors will have much smaller payout times.

\section{RADIANT HEAT LOADS AND LOW-EMISSIVITY CEILINGS}

A major heat source in all ice rinks is infrared radiation from the ceiling (and walls, to a lesser extent). The one variable affecting the radiant heat load that can be controlled is the emissivity of the ceiling. Covering the ceiling with a false ceiling made of a low-emissivity material, such as aluminum foil, or painting the ceiling with a low-emissivity aluminum-base paint will greatly reduce the refrigeration load.

The radiant heat load can be calculated as follows: ${ }^{3}$

$$
Q=\sum_{j} A_{j} f_{j-i} \sigma\left(T_{j}^{4}-T_{i}^{4}\right)
$$

where the subscript $j$ refers to the hotter radiating walls and ceiling and the subscript $i$ refers to the ice surface; $A_{j}$ is the area of the surface $j ; \sigma$ is the Stephan-Boltzman constant; and $f_{j-i}$ is the gray-body configuration factor for the net radiation from surface $j$ to surface $i$. The summation is over all isothermal surfaces, and $f$ is given by 3,14

$$
f_{j-i}=\left[\frac{1}{F_{j-i}}+\left(\frac{1}{\epsilon_{j}}-1\right)+\frac{A_{j}}{A_{1}}\left(\frac{1}{\epsilon_{1}}-1\right)\right]^{-1}
$$


where $\epsilon_{j}$ is the emissivity of the surface $j$, and the view factor, $F_{j-i}$, is defined as follows: ${ }^{3,14}$

$$
F_{j-i}=\frac{1}{\left(A_{j} \pi\right)} \iint \frac{\cos \theta_{j} \cos \theta_{i} d A_{j} d A_{i}}{r_{j i}^{2}}
$$

In Eq. 13, $\theta_{\mathrm{i}}$ is the angle between the normal to the differential area $d A_{i}$ and the line segment $r_{j i}$ connecting $d A_{j}$ and $d A_{j}$.

For complex geometries, $F_{j-i}$ can be experimentally measured with scale models.14,15 However, if the geometry can be reduced to an equivalent right parallelogram, $F_{j-i}$ can be read from graphs of $F_{j-i}$ as a function of aspect ratios of the parallelogram.

The layout of a normal ice rink with two common roof styles is shown in Fig. 23. The geometries of the two roofs, from which the view factors were calculated, were simplified in two different ways. The geometries of both roofs were changed to a flat ceiling at the midheight of the actual ceiling, as indicated by the dashed line in Fig. 23 . The effective area for radiation and the view factors for the two roofs, however, were calculated differently.

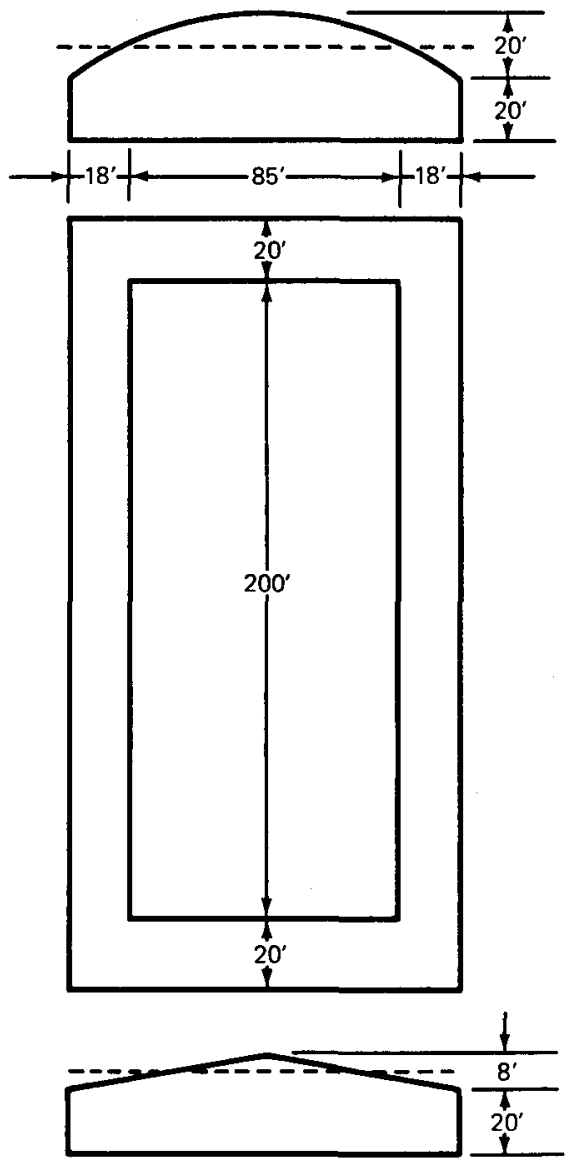

Fig. 23 Rink geometry with two roof styles.
For the circular ceiling, the effective radiating area is greater than the area directly over the ice surface because the circular shape focuses radiation onto the ice. The effective radiating area of the circular ceiling was assumed to extend until the normal to the ceiling no longer intercepted the ice surface. With this assumption the effective width of the ceiling for the rink shown in Fig. 23 is $123 \mathrm{ft}$, rather than the $85 \mathrm{ft}$ that is directly over the ice surface. Therefore, the effective radiating area of the ceiling is $123 \times 200 \mathrm{ft}^{2}$, or $24,600 \mathrm{ft}^{2}$. This procedure neglects the 20 - $\mathrm{ft}$-wide end aisles that do not focus onto the ice.

The view factor for the circular ceiling was then calculated as if the ceiling and ice were parallel opposed rectangles, even though the ceiling area is $45 \%$ greater than that of the ice surface. This assumption is justified by the definition of the effective width of the ceiling, i.e., a normal from the edge of the ceiling intercepts the edge of the ice, as is the case for parallel opposed rectangles. For parallel rectangles, $123 \mathrm{ft}$ by $200 \mathrm{ft}$, separated by $30 \mathrm{ft}$, the view factor is $0.71 .^{14}$

For the shallow peaked ceiling, an average view factor was calculated by averaging the view factor for the area directly over the ice and the view factors for the ceiling areas directly over the side and end aisles. The view factors were weighted by their respective ceiling areas:

$$
F_{\text {av. }}=\frac{A_{\text {ice }} F_{\text {ice }}+A_{\text {side }} F_{\text {side }}+A_{\text {end }} F_{\text {end }}}{A_{\text {total }}}
$$

The side- and end-aisle view factors were calculated by treating the ceiling areas over the aisles as line radiation sources to the ice. This procedure gave an average view factor of 0.49 for the peaked roof.

The view factor for the walls is more complicated since the dashers block some of the radiation from the wall and there is an aisle between the ice and the wall. The simplified geometry for wall radiation is shown in Fig. 24 . It is assumed that only the upper half of the walls (region 1) radiate to the ice (region 4 ). This assumption is justified because:

- The dashers act as a radiation shield for the lower wall.

- The lower wall has a very small view factor to the ice.

- The wall is not isothermal, and the temperature of the lower half of the wall is close to that of the ice. Hence, there will be little net radiation to the ice.

It is also assumed that the dashers block wall radiation to the $5 \mathrm{ft}$ of ice adjacent to the dasher. Therefore, the view factor for wall radiation to the ice is approximately $F_{1-4}$ with regions 1 and 4 shown in Fig. 24.

The value of $F_{1-4}$ can be found by the method of decomposition. ${ }^{14}$ With this method, the view factor for one large surface is broken down into view factors and areas of smaller subregions as shown in Eq. 15, 


$$
A_{3,4} F_{3,4-2}=A_{3} F_{3-2}+A_{4} F_{4-2}
$$

where the subscripts refer to the regions of Fig. $24 ; A_{3,4}$ is the area of regions 3 and 4 ; and $F_{3,4-2}$ is the view factor for radiation from regions 3 and 4 , taken as a whole, to region 2 . Also of use is the identity

$$
A_{1} F_{1-3}=A_{3} F_{3-1}
$$

With Eqs. 15 and 16, the view factor $F_{1-4}$ can be found from the view factors $F_{3,4-1}, F_{3-1,2}, F_{3,4-2}$, and $F_{3-2}$, all of which are for perpendicular rectangular areas and are readily available from graphs. ${ }^{15}$ The derivation of $F_{1-4}$, where the starred view factors can be found from graphs, is as follows:

$$
\begin{aligned}
& A_{3,4} F_{3,4-1,2}^{*}=A_{3} F_{3-1,2}^{*}+A_{4} F_{4-1,2} \\
& A_{4} F_{4-1,2}=A_{1,2} F_{1,2-4}=A_{1} F_{1-4}+A_{2} F_{2-4} \\
& A_{2} F_{2-4}=A_{4} F_{4-2}=A_{3,4} F_{3,4-2}^{*}-A_{3} F_{3-2}^{*}
\end{aligned}
$$
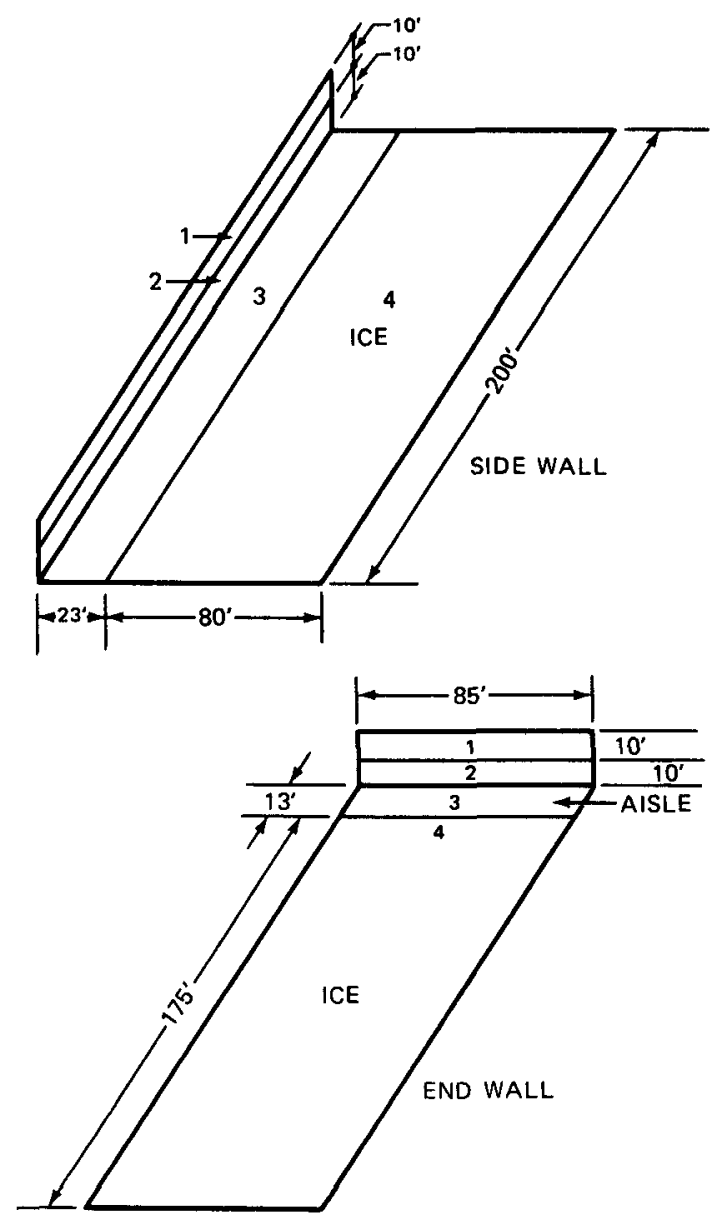

Fig. 24 Simplified geometry for wall radiation calculations.
Solving for $F_{1-4}$,

$$
\begin{aligned}
F_{1-4}=\left(A_{3,4} F_{3,4-1,2}^{*}-A_{3} F_{3-1,2}^{*}\right. & \\
& \left.+A_{3} F_{3-2}^{*}-A_{3,4} F_{3,4-2}^{*}\right)\left(A_{1}\right)^{-1}
\end{aligned}
$$

The view factors for radiation from the walls to the ice can then be calculated from Eq. 17 and the data below.

For the side walls,

$$
\begin{array}{ll}
F_{3,4-1,2}^{*}=0.080 & A_{1}=A_{2}=2000 \mathrm{ft}^{2} \\
F_{3-1,2}^{*}=0.27 & A_{3}=4600 \mathrm{ft}^{2} \\
F_{3,4-2}^{*}=0.03 & A_{4}=16,000 \mathrm{ft}^{2} \\
F_{3-2}^{*}=0.13 &
\end{array}
$$

and $F_{1-4}$ is calculated to be 0.193 . For the end walls,

$$
\begin{array}{ll}
F_{3,4-1,2}^{*}=0.023 & A_{1}=A_{2}=850 \mathrm{ft}^{2} \\
F_{3-1,2}^{*}=0.328 & A_{3}=1105 \mathrm{ft}^{2} \\
F_{3,4-2}^{*}=0.023 & A_{4}=16,575 \mathrm{ft}^{2} \\
F_{3-2}^{*}=0.278 &
\end{array}
$$

and $F_{1-4}=0.268$.

Once the view factors are known, the gray-body configuration factor, $f$, can be calculated for ceilings with various emissivities. The surfaces and their emissivities ${ }^{7,8}$

\begin{tabular}{|c|c|c|c|c|c|}
\hline & \multirow{2}{*}{$\begin{array}{c}\text { Radiating } \\
\text { area, } \\
10^{3} \mathrm{ft}^{2}\end{array}$} & \multirow[b]{2}{*}{$\mathbf{F}$} & \multicolumn{3}{|c|}{$f$ for $\epsilon=$} \\
\hline & & & 0.90 & 0.24 & 0.04 \\
\hline Round ceilıng & 24.6 & 0.61 & 0.555 & 0.206 & 0.039 \\
\hline Peaked ceılıng & 27.0 & 0.49 & 0.457 & 0.190 & 0.038 \\
\hline End walls & 1.70 & 0.19 & 0.189 & 0.120 & 0.034 \\
\hline Side walls & 4.00 & 0.27 & 0.259 & 0.145 & 0.036 \\
\hline
\end{tabular}
are: ice, 0.95; wood, 0.90; low-emissivity aluminized paint, 0.24 ; and polished aluminum foil, 0.04 . Table 16 lists the values for $f$ calculated by Eq. 12 .

In addition to the emissivity and the geometry of the radiating surface, the radiant heat load depends on the absolute temperature raised to the fourth power, as shown in Eq. 11. However, since the temperature varies from day to night and from season to season, an average temperature must be used. The variations in the absolute temperature are small $( \pm 2 \%)$. Hence, an average daily temperature was used in calculating the radiant heat load by Eq. 11 . Figure 25 shows the radiant heat flux to the ice as a function of temperature for a shallow peaked roof. It can

Table 16 Gray-Body Configuration Factors $(f)$ for Ice Rinks 
be seen that the heat flux is approximately linear over a $20^{\circ} \mathrm{F}$ range.

The ceiling temperature at Orr Rink was measured periodically during February and March, and the average temperatures were $55^{\circ} \mathrm{F}$ during the day and $45^{\circ} \mathrm{F}$ during the night. At North Adams the temperatures were somewhat lower, $50^{\circ} \mathrm{F}$ and $40^{\circ} \mathrm{F}$ for day and night, respectively. The ice surface temperatures at Orr Rink were $18^{\circ} \mathrm{F}$ at night and $20^{\circ} \mathrm{F}$ during the day. At North Adams the surface temperature was $26^{\circ} \mathrm{F}$. The radiant heat loads calculated using these temperatures were $6.46 \times 10^{6} \mathrm{Btu} / 16-\mathrm{hr}$ day and $2.39 \times 10^{6} \mathrm{Btu} / 8$-hr night at Orr Rink (round ceiling) and $4.75 \times 10^{6}$ Btu/24-hr day for North Adams (shallow peaked ceiling). These values were used in constructing the heat balances in App. 3.

The radiant heat load can be reduced either by reducing the ceiling temperature or by covering the ceiling with a material of lower emissivity. Lowering the ceiling temperature is impractical since the ceiling must be kept warm to prevent water vapor from condensing on the ceiling and dripping onto the ice. In fact, normal operating procedure is to heat the ceiling to keep the ceiling temperature above the wet bulb temperature of air. Therefore, covering the ceiling with a low-emissivity material is the only practical method of reducing the radiative heat load of an ice rink.

Relatively little of the radiation emitted by the walls is absorbed by the ice, as evidenced by the low view factors for the walls in Table 16. For this reason, only the ceiling need be covered with a low-emissivity material. Two materials are commercially available for this purpose: an aluminumfoil-faced false ceiling $(\epsilon=0.04)$ and an aluminum-base low-emissivity paint $(\epsilon=0.24)$.

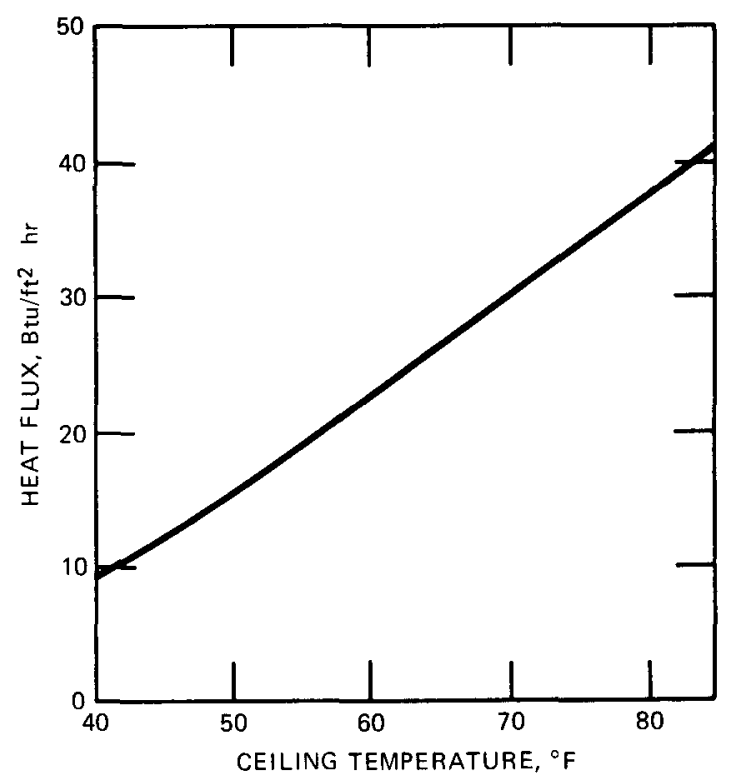

Fig. 25 Radiant heat flux vs. ceiling temperature.
Besides a reduced radiant heat load, there are two additional areas of energy savings that can be achieved by Installing a low-emissivity ceiling. First, an aluminum-colored ceiling will reflect more light to the ice, permitting a lowering of the light intensity. A $4-\mathrm{kW}$ reduction in light power $(8 \%$ to $10 \%$ of the power for the lights directly over the ice) was included in the calculation of energy savings for both the painted and false ceilings. ${ }^{16}$ it was also assumed that the refrigeration heat load would be reduced by $2 \mathrm{~kW}$ owing to the reduction in light power. Second, with a reduction in the amount of heat radiated to the ice, the ceiling will be warmer. The installation of an aluminum false ceiling has been estimated to raise the temperature of the ceiling by $10^{\circ} \mathrm{F}^{17}$ and this rise in temperature reduces the space heating requirements. The University of Delaware reported a $30 \%$ decrease in the volume of gas used to heat their skating rink in the year following the installation of a false ceiling. ${ }^{18}$ For the calculation of energy savings from a false ceiling, a gas credit of $25 \%$ of the average gas bill $(\$ 14,000)$ for Massachusetts rinks was added to the lighting and refrigeration savings. For low-emissivity paint, a gas credit of $15 \%$ was used in the calculation of total dollar savings. Two-thirds of the gas credit was applied to the winter season, and the remaining one-third, to the spring and fall.

Table 17 summarizes the calculated radiant heat loads, costs of refrigeration for the radiant heat load, and the total expected dollar savings from installing a low-emissivity ceiling. The calculations for the radiant heat load were done for three time periods with different average temperatures: winter ( 5 months and $50^{\circ} \mathrm{F}$ ); spring/fall $(4$ months and $\left.60^{\circ} \mathrm{F}\right)$; and summer $\left(3\right.$ months and $\left.70^{\circ} \mathrm{F}\right)$. These temperatures are for a wood ceiling. The temperatures used were $5^{\circ} \mathrm{F}$ higher for the low-emissivity painted ceiling and $10^{\circ} \mathrm{F}$ nıgher for the aluminum false ceiling. The ice surface

Table 17 Radiant Heat Loads and Dollar Savings for Low-Emissivity Ceilings

\begin{tabular}{|c|c|c|c|c|}
\hline Period & $\begin{array}{l}\text { Ceiling } \\
\text { material }\end{array}$ & $\begin{array}{c}\text { Radiant } \\
\text { heat load, } \\
10^{8} \mathrm{Btu}\end{array}$ & $\begin{array}{c}\text { Cost of } \\
\text { refrigeration, } \\
\$\end{array}$ & $\begin{array}{c}\text { Total } \\
\text { expected } \\
\text { savings, \$ }\end{array}$ \\
\hline \multirow[t]{3}{*}{ Wınter } & Wood & 10.4 & 3,737 & \\
\hline & Low-e paint & 5.18 & 1,830 & 3,743 \\
\hline & Al. foll & 1.18 & 419 & 6,154 \\
\hline \multirow{3}{*}{$\begin{array}{l}\text { Sprıng/ } \\
\text { fall }\end{array}$} & Wood & 11.1 & 3,970 & \\
\hline & Low-e paint & 5.33 & 1,886 & 2,953 \\
\hline & Al. foll & 1.25 & 441 & 4,798 \\
\hline \multirow[t]{3}{*}{ Summer } & Wood & 10.5 & 3,764 & \\
\hline & Low-e paint & 4.96 & 1,753 & 2,213 \\
\hline & Al, foll & 1.14 & 403 & 3,563 \\
\hline Total & Wood & 32.0 & 11,471 & \\
\hline for & Low-e paint & 15.47 & 5,473 & 8,909 \\
\hline year & Al. foll & 3.57 & 1,263 & 14,515 \\
\hline
\end{tabular}


temperatures used in the calculations were $22^{\circ} \mathrm{F}$ (winter), $24^{\circ} \mathrm{F}$ (spring/fall), and $26^{\circ} \mathrm{F}$ (summer). The cost of refrigeration is for a conventional Freon/brine refrigeration system (COP $=2.9$ ). Rinks with a direct refrigeration system will have $15 \%$ smaller savings (ratio of COP values, $2.9 / 3.4$, and rinks with rounded ceilings will have $10 \%$ greater savings because of the greater product of the $f$ factor and the radiating area.

The calculated radiant heat loads show excellent agreement with measured reductions in electric energy use. The Wissahickon Skating Club in Philadelphia installed an aluminum false ceiling in 1977, and electrical logs showed a reduction of $2.6 \times 10^{5} \mathrm{kWh}$ of electricity in the following year for an 11-month season. ${ }^{16}$ This figure is exactly equal to that estimated from Table $17,2.6 \times 10^{5} \mathrm{kWh}$. This estimate is calculated by taking $1 \frac{1}{12}$ of the annual radiant heat load and assuming a COP of 2.9 .

\section{SPACE HEATING}

The cost of gas for an ice rink is surprisingly high. For Massachusetts state-owned rinks, the average gas bill was $\$ 14,000$ in 1977 for a 7.5 -month season. ${ }^{6}$ This value is about $50 \%$ of the total electric utility bill. Twenty-five percent of the gas is used for heating hot water, which is used for snow melting $(\$ 1400)$, resurfacing water $(\$ 1000)$, and showers (est. at $\$ 1000$ ). The remaining $75 \%$ of the gas $(\$ 10,000)$ is used for space heating. This value of $\$ 10,000$ per year for space heating cost in Massachusetts has been reported for Orr Rink also. 19

The condenser of the refrigeration system can be the source of most, if not all, the heat needed for space heating. One problem with using condenser waste heat for space heating, however, is that the amount of heat available is least during the winter months, when the demand for space heating is greatest.

The amount of heat available for space heating during December, January, and February was calculated and compared with the actual gas consumption for those months for two rinks. The first rink, North Adams, has a conventional Freon/brine refrigeration system and average electricity and gas bills. The second rink, Holyoke, has a direct Freon refrigeration system and the lowest electric energy use of Massachusetts state-owned rinks. However, gas consumption at the Holyoke rink was slightly above average. Table 18 summarizes the electric energy use and compares the condenser waste heat with the heat content of the gas consumed by the rink in the same month.

The electric energy use and gas consumption shown in Table 18 were taken from logs kept by the rink managers. ${ }^{6}$ The amount of condenser waste heat was calculated from Eq. 5 with $A=0.8$, and the space heating requirements were estimated at $75 \%$ of the gas consumption. The North Adams rink has a conventional Freon/brine refrigeration system, and Holyoke has a direct expansion system. As can be seen in Table 18, even rinks with low electric energy use still have enough waste heat available to provide for space heating.

\section{NEW LIGHTING SYSTEMS}

Modern lighting systems, such as high-pressure sodium and fluorescent systems, are much more efficient than the mercury system found in most older rinks. The exact savings that can be achieved from changing to one of the newer systems depends on the relative efficiency of the lighting, the light intensity required for the rink, the number of hours of operation, and the season length. Table 19 lists the efficiencies of the various lighting systems $^{20}$ and the operating costs per month for an 18-hr operating day at a light intensity of 55 footcandles. Two levels of light intensity were used for mercury lighting since the light intensity at rinks with mercury systems is often lower than the intensity at rinks with the newer systems. $^{4,21}$

The operating costs for mercury and high-pressure sodium lighting are taken from a consulting report; ${ }^{21}$ the values for fluorescent lighting are calculated from the relative lighting efficiencies. The marginal refrigeration savings are for a conventional Freon/brine system calculated by Eq. 4 with the assumption that half the energy used by the lighting is removed by the refrigeration system.

Table 18 Availability of Condenser Waste Heat

\begin{tabular}{cccccc}
\hline Rink & Month & $\begin{array}{c}\text { Actual } \\
\mathbf{1 0 ^ { 4 }} \mathbf{~ k W h} / \\
\text { month }\end{array}$ & $\begin{array}{c}\text { Estimated } \\
\text { condenser } \\
\text { heat, } \\
\mathbf{1 0 ^ { 8 }} \mathbf{B t u}\end{array}$ & $\begin{array}{c}\text { Actual } \\
\text { gas } \\
\text { consumption, } \\
\mathbf{1 0 ^ { 8 }} \mathbf{B t u}\end{array}$ & $\begin{array}{c}\text { Condenser heat } \\
\text { as \% of space } \\
\text { heat needs }\end{array}$ \\
\hline North & Dec. & 7.38 & 6.04 & 5.40 & 149 \\
Adams & Jan. & 7.69 & 6.30 & 6.46 & 130 \\
& Feb. & 7.98 & 6.53 & 5.71 & 152 \\
Holyoke & Dec. & 4.93 & 5.57 & 6.20 & 120 \\
& Jan. & 4.45 & 5.03 & 6.21 & 108 \\
& Feb. & 6.08 & 6.87 & 6.59 & 139 \\
\hline
\end{tabular}


The 55-footcandle light intensity used in Table 19 is the light requirement for hockey. Figure and general skating require significantly lower light intensities (10 to 15 footcandles). ${ }^{22}$ Therefore most rinks will not realize the full savings implied by Table 19. Table 20 gives the range of savings for new lighting systems which can be expected by rinks with mixed skating uses and shorter skating days. In the calculations for Table 20 , the refrigeration and electricity costs in Table 19 were prorated. The lamp replacement cost was assumed to be fixed by the highest light intensity and not prorated.

\section{INTEREST CHARGES}

The payout times for new equipment calculated for the manual did not include interest charges on the capital investment because the payout times are a stronger function of season length than of interest rates. However, Fig. 18 can be used to correct the payout times for interest charges. Figure 18 is based on Eqs. 18 and 19 for the present value (P) of an investment and an annuity, respectively,

$$
\begin{gathered}
P=I(1+i / 12)^{n} \\
P=\frac{I\left[(1+i / 12)^{n}-1\right]}{\left(n_{0} i / 12\right)}
\end{gathered}
$$

Where $\mathrm{n}$ is the payout time (in months) with interest charges included, $n_{0}$ is the payout time without interest, 1 is the total initial investment, and $i$ is the annual interest rate. Note that the annual dollar savings from an investment in new equipment is $1 / n_{0}$, which is the annuity payment value in Eq. 19.

If the present values of both the single investment and the annuity are equated, Eqs. 18 and 19 can be solved for $n$ as a function of $n_{0}$ for a given interest rate, $i$. The curves of Fig. 18 summarize these calculations.

\section{CALCULATION OF INTERACTION FACTORS}

The savings for each change in rink operation were calculated independently. The actual savings from any one modification in rink operation, however, depend on the other changes that are made at the same time. This dependence of the savings on the total of all the changes

Table 19 Efficiency and Operating Costs for Lighting Systems for 18-hr Day

\begin{tabular}{lcccc}
\hline & $\begin{array}{c}\text { High-pressure } \\
\text { sodium (55 } \\
\text { footcandles) }\end{array}$ & $\begin{array}{c}\text { Fluorescent } \\
\text { (55 footcandles) }\end{array}$ & $\begin{array}{c}\text { Mercury } \\
\text { (55 footcandles) }\end{array}$ & $\begin{array}{c}\text { Mercury } \\
\text { (39 footcandles) }\end{array}$ \\
\hline $\begin{array}{c}\text { Efficiency, } \\
\text { lumens/watt } \\
\text { Cost of elec- } \\
\text { tricity, \$/month } \\
\begin{array}{c}\text { Lamp replacement } \\
\text { cost, \$/month }\end{array}\end{array}$ & 125 & 71 & 46 & 46 \\
$\begin{array}{c}\text { Refrigeration } \\
\text { costs, \$/month }\end{array}$ & 31 & 586 & 902 & 640 \\
$\begin{array}{c}\text { Total operating } \\
\text { costs, \$/month }\end{array}$ & 423 & 101 & 51 & 36 \\
\hline
\end{tabular}

\begin{tabular}{|c|c|c|c|c|}
\hline $\begin{array}{l}\text { Hours of } \\
\text { light use }\end{array}$ & $\begin{array}{l}\text { High-pressure } \\
\text { sodium (55 } \\
\text { footcandles) }\end{array}$ & $\begin{array}{c}\text { Fluorescent } \\
\text { (55 footcandles) }\end{array}$ & $\begin{array}{c}\text { Mercury } \\
\text { (55 footcandles) }\end{array}$ & $\begin{array}{c}\text { Mercury } \\
\text { (39 footcandles) }\end{array}$ \\
\hline $\begin{array}{c}8 \mathrm{hr} \text { at full power }+ \\
8 \mathrm{hr} \text { at } 15 \text { foot- } \\
\text { candles, } \$ / \text { month } \\
6 \mathrm{hr} \text { at full power }+ \\
10 \mathrm{hr} \text { at } 15 \text { foot- } \\
\text { candles, } \$ / \text { month } \\
6 \mathrm{hr} \text { at full power }+ \\
6 \mathrm{hr} \text { at } 15 \text { foot- } \\
\text { candles, } \$ / \text { month }\end{array}$ & 253 & 389 & 564 & 446 \\
\hline
\end{tabular}

Table 20 Lighting Costs for Rinks with Mixed Skating 
made in' rınk operation is especially evident for the use of condenser waste heat for space heating. For example, the installation of a nonradiative false ceiling reduces the heat load by between $25 \%$ and $30 \%$. Therefore, the amount of waste heat available for space heating is reduced to between $70 \%$ and $75 \%$ of the amount available in the absence of the false ceilıng.

Table 6 itemizes the factors by which each modification in rink operation affects all the other possible modifications. Most of the factors under the column of Table 6 labeled "space heating" are obtained from fractional reductions in heat loads. The exceptions are for "snowmelting kit" and "load-cyclıng controller." For the "snowmelting kit," the factor 0.94 is obtained from the fraction of condenser heat $(6 \%)$ that is used to melt snow. The 0.80 factors opposite "load-cycling controller" are calculated from the measured $20 \%$ increase in refrigeration efficiency. ${ }^{20}$ The increase in efficiency is due to a reduction in the time that the compressors, pumps, and fans are runnıng. Therefore, there are no further reductions in energy use available for turning off the compressors and pumps at night, and the factors for these two changes are 0.

The factors listed horizontally under "nonradiative ceilıng" in Table 6 are calculated from the reduction in the difference between the ceiling and the ice surface temperatures raised to the fourth power. For the "load-cycling controller" and "increase power factor with capacitors" entries, the reductions in savings were calculated at $80 \%$ of the reductions in heat loads since the load-cycling controller and capacitor include savings in the operating costs of pumps and fans, which are not affected by changes in the heat load. Therefore, the reduction in savings for a capacitor when a nonradiative ceiling is installed is only $20 \%$ rather than the full $25 \%$ reduction in heat load.

The savings for "raise brine temperature" are reduced $43 \%$ by the installation of a "nonradiative ceiling" because the radiant heat load is $43 \%$ of the sum of the convective and radiant heat loads, which are the only two heat loads affected by a change in refrigerant temperature. The calculation of the other factors in Table 6 is straightforward.

\section{REFERENCES}

1. Bullding and Maıntaınıng a Better /ce Surface, Frank J. Zambonı Co., Paramount, Calif

2. H. J. Maclntıre and F. W. Hutchınson, Refrigeration Engıneering, John Wiley \& Sons, New York, 1950.

3. R. B. Bird, W. E. Stewart, and E. N. Lightfoot, Transport Phenomena, John Wiley \& Sons, New York, 1960.

4. Personal communication, John Connelly, Rınk Design Consultants, Syracuse, $N Y$.

5. A. Bennett, Ed., ASHRAE Handbook, American Society of Heatıng, Refrigeratıng, and Aır-Conditioning Engıneers, New York, 1978.

6. Personal communication, Paul Hogan, Superıntendent of Rınks and Pools, Department of Environmental Management, State of Massachusetts.

7. C. D. Hodgman, Ed., Handbook of Chemistry and Physics, Chemıcal Rubber Publıshıng Co., Cleveland, 1959.

8. W. H. McAdams, Heat Transmission, McGraw-Hıll Book Company, New York, 1942.

9. Personal communication, Department of Sewers and Water, Northampton, Mass.

10. Personal communication, Berkshıre Gas Co., Greenfield, Mass.

11. Personal communication, G. Shean, Engıneer in Charge of Construction for Waterways, State of Massachusetts.

12. Power Factor Correction, Sprague Electric Co.. North Adams, Mass.

13. Personal communicatıon, John Ballentıne, engıneer for Sprague Electric Co., North Adams, Mass.

14. Jakob, Heat Transfer, John Wiley \& Sons, New York, 1957

15. T. J. Love, Radiative Heat Transfer, C. E. Merrill, Columbus, Ohı, 1968.

16. Personal communication, Walter Muehlbronner, Manager, Wissahıckon Skatıng Club, Phıladelphıa, Pa.

17. C. D. MacCracken, Engıneering Contributıons to the Ice Rink Industry, ASHRAE J., 16. 36 (1974).

18. Personal communıcatıon, J. O'Neıl, Rınk Manager, Unıversıty of Delaware

19. Willıam Mueller, Engıneering Report on Orr Rınk, Amherst College, Amherst, Mass.

20. Personal communication, Cliff Forester, Western Massachusetts Electric Co., Greenfield, Mass.

21. Light Cost Analysis for Williston Academy Hockey Rink, General Electric Lıghtıng Systems.

22. Devoe Environmental Systems, Bulletın 1-40, Carlstadt, N. J. 


\section{Appendix $5 \quad$ Heat and Mass Transfer Coefficients}

The convective heat terms in the heat balances given in Tables 8 through 11 were obtained by subtracting all the other heat terms from the total heat flux. The accuracy of this method is in some doubt since small errors in the other terms may give a large relative error in the convective heat term. Furthermore, ASHRAE ${ }^{1}$ has estimated that the convection heat load is much smaller $(27 \%)$ than that in the present work $(40 \%)$.

In this Appendix, the heat and mass transfer coefficients between the air and the ice surface are calculated from the measured convective heat load for several different rink conditions. The convective heat transfer coefficient, $h$, can then be compared with the coefficient predicted by Eq. 9 in Appendix 4, which is an empirical formula used to estimate air conditioning loads, ${ }^{2}$

$$
h=0.6+0.28 \mathrm{~V}
$$

The velocity, $V$, in this equation, required to give the calculated $h$, can be used to determine whether or not the convective heat loads are reasonable.

The convective heat load (including the latent heat effect of convective mass transfer) is given by Eq. 20:

$$
\begin{aligned}
Q=h\left(T_{\text {air }}-T_{\text {ice }}\right)+k\left(x_{\text {air }}-x_{\text {Ice }}^{\text {sat }}\right) \\
\\
\quad x(1226 \mathrm{Btu} / \mathrm{lb})(18 \mathrm{lb} / \text { mole })
\end{aligned}
$$

where the mass transfer coefficient, $k$, is estimated by the Chilton Colburn analogy ${ }^{3}$

$$
k=\frac{h}{C_{p}}\left(\frac{P r}{S c}\right)^{2 / 3}=\frac{h}{6.98}\left(\frac{0.74}{0.56}\right)^{3 / 3}=0.17 h
$$

and the mole fraction of water vapor in air, $x_{a i r}$, is calculated using a relative humidity of $80 \%$. The temperatures, mole fractions, heat loads, and calculated heat transfer coefficients are tabulated in Table 21 for four different rink conditions.

The average heat transfer coefficient is $0.88 \mathrm{Btu} /$ $\mathrm{ft}^{2} \cdot \mathrm{hr} \cdot{ }^{\circ} \mathrm{F}$. This value for $\mathrm{h}$ corresponds to an air velocity of about $1 \mathrm{mph}$, by Eq. 9 , which is a reasonable air velocity within the rink at ice level.

If the sensible and latent heat effects in Eq. 20 are compared, the latent heat effect is seen to be half that of the sensible heat effect. Increasing the relative humidity to $100 \%$ will only increase the latent heat effect to $80 \%$ of the sensible heat. However, ASHRAE ${ }^{1}$ estimates that the latent heat load is $15 \%$ greater than the sensible heat. If this estimate is correct, the mass transfer coefficient must be at least $43 \%$ greater than that estimated by the Chilton Colburn analogy.

In conclusion, the heat transfer coefficient calculated from the convective heat loads are not unreasonable for an ice rink. Hence, the heat balances and the calculations of savings in refrigeration costs, which are based on the heat balances, are also reasonable.

\section{REFERENCES}

1. Personal communication, John Connelly, Rink Design Consultants, Syracuse, N. Y.

2. H. J. Maclntire and F.W. Hutchinson, Refrigeration Engineering, John Wiley \& Sons, New York, 1950.

\begin{tabular}{|c|c|c|c|c|}
\hline & \multicolumn{3}{|c|}{ Orr Rink } & \multirow{2}{*}{$\begin{array}{c}\text { North Adams } \\
24 \mathrm{hr} \\
\text { (light use) }\end{array}$} \\
\hline & $\begin{array}{c}\text { Night } \\
\text { (compressor on) }\end{array}$ & $\begin{array}{c}\text { Night } \\
\text { (compressor off) }\end{array}$ & Day & \\
\hline $\mathrm{Q}, \mathrm{Btu} / \mathrm{ft}^{2} \cdot \mathrm{hr}$ & 29 & 19 & 29 & 16 \\
\hline $\mathrm{T}_{\text {Ice }}{ }^{\circ} \mathrm{F}$ & 18 & 23 & 20 & 26 \\
\hline $\mathrm{T}_{\text {alr. }}{ }^{\circ} \mathrm{F}$ & 37 & 37 & 40 & 40 \\
\hline $10^{-3} x_{\text {air }}$ & 5.90 & 5.90 & 6.62 & 6.62 \\
\hline $10^{-3} x_{\text {ice }}^{\text {sat }}$ & 3.12 & 3.96 & 3.43 & 4.57 \\
\hline $\mathrm{h}, \mathrm{Btu} / \mathrm{ft}^{2} \cdot \mathrm{hr} \cdot{ }^{\circ} \mathrm{F}$ & 0.98 & 0.89 & 0.91 & 0.73 \\
\hline
\end{tabular}

3. R. B. Bird, W. E. Stewart, and E. N. Lightfoot, Transport Phenomena, John Wiley \& Sons, New York, 1960.

Table 21 Heat Transfer Coefficients for the Ice Surface 